\title{
Consumo de Água pela Cultura do Crisântemo Envasado, Cultivar Puritan, sob Condições de Estufa.
}

\author{
RAQUEL APARECIDA FURLAN \\ Engenheiro Agrônomo
}

Orientador: Prof. Dr. Tarlei Arriel Botrel

\begin{abstract}
Dissertação apresentada à Escola Superior de Agricultura "Luiz de Queiroz", da Universidade de São Paulo, para obtenção do Título de Mestre em Agronomia, Área de concentração: Irrigação e Drenagem.
\end{abstract}

PIRACICABA

Estado de São Paulo - Brasil

agosto de 1996 
Dados Internacionais de Catalogação na Publicação (CIP)

DIVISÃo DE BIBLIOTECA E DOCUMENTAÇẪO - Campus "Luiz de Queiroz"/USP

Furlan, Raquel Aparecida

Consumo de água pela cultura do crisântemo envasado, cultivar puritan, sob condiçōes de estufa / Raquel Aparecida Furlan. - - Piracicaba, 1996.

65 p. : il.

Dissertação (mestrado) - - Escola Superior de Agricultura Luiz de Queiroz, 1996.

Bibliografia.

1. Água em crisântemo - Consumo - Avaliação 2. Crisântemo - Cultivo em vaso 3. Estufa 4. Evapotranspiração I. Titulo

CDD 635.93355 


\title{
Consumo de Água pela Cultura do Crisântemo Envasado, Cultivar Puritan, sob Condições de Estufa.
}

\author{
RAQUEL APARECIDA FURLAN
}

Aprovada em: 07 de outubro de 1996

Comissão julgadora:

Prof. Dr. Tarlei Arriel Botrel

ESALQ/USP

Prof. Dra. Ana Maria Liner Pereira Lima ESALQ/USP

Prof. Dr. Marcos Vinícius Folegatti

ESALQ/USP

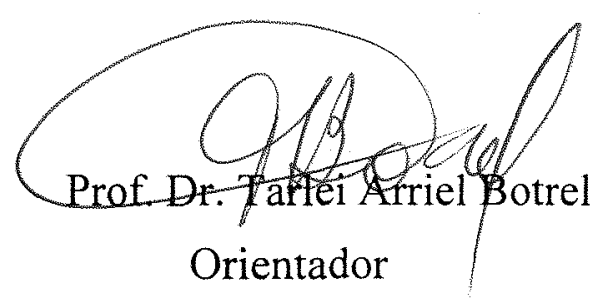


AOS MEUS PAIS EDENIR PEDRO FURLAN, MARIA DE LOURDES GANASSIM FURLAN, POR TODO AMOR E DEDICAÇA $O$

Oifferreço 


\section{AGRADECIMENTOS}

Ao professor Dr. Tarlei Arriel Botrel, pela orientação e pelo apoio e confiança depositada em meu trabalho;

Aos professores do Departamento de Engenharia Rural e do Departamento de Física e Meteorologia da ESALQ/USP pelos ensinamentos proferidos e pela amizade;

A coordenação de Aperfeiçoamento de Pessoal de Nível Superior (CAPES), pela bolsa de estudo concedida;

A família Scholten, em especial à Ricardo Afonso Scholten por ter permitido que este trabalho fosse realizado em sua propriedade;

A José Luis e Renato, funcionários da Granja Triângulo pela dedicação e ajuda;

A Renato Optiz (Veiling Holambra) e a professora Ana Maria Liner Pereira Lima (ESALQ/USP), pela colaboração e apoio;

Ao professor Dr. Antônio Sanches de Oliveira pela colaboração e apoio;

Aos professores Nilson Augusto Villa Nova, Klaus Nicolaus Reichardt e Marcos Vinícius Folegatti pela amizade e colaboração;

Aos colegas de curso pela presença amiga tanto nos momentos felizes como nas adversidades; 
Aos funcionários do Departamento de Engenharia Rural, Antonio César Souza Rocha, Gilmar Batista Grigolon, Hélio Toledo Gomes, José Figueiredo, Silvia Aparecida Camargo e Vera Lúcia José Miguel pela colaboração e amizade;

A Anderson Soares Pereira, pela sua contribuição na elaboração deste trabalho;

A Maria de Lourdes Ganassim Furlan, pelo apoio e pela ajuda na execução do trabalho.

A todos aqueles que contribuíram em qualquer etapa para a realização deste trabalho. 


\section{SUMÁRIO}

\section{Página}

LISTA DE FIGURAS..................................................................................

LISTA DE TABELAS............................................................................ xii

LISTA DE SÍMBOLOS...................................................................... xiv

RESUMO

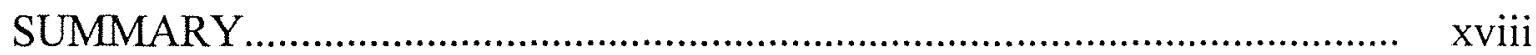

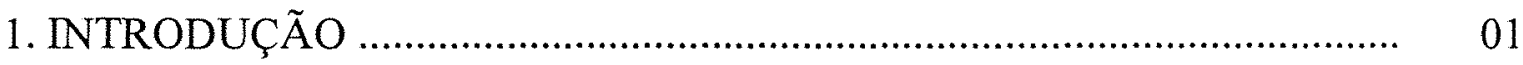

2. REVISÃO DE LITERATURA …............................................................. 03

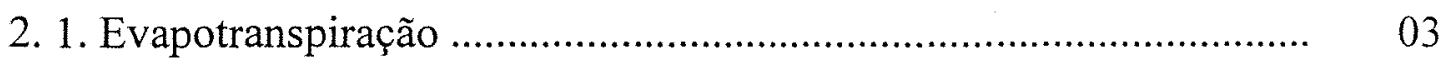

2.1.1. Radiação Solar no Interior de Estufas .................................... 09

2.1.2. Tanque Classe A ............................................................... 11

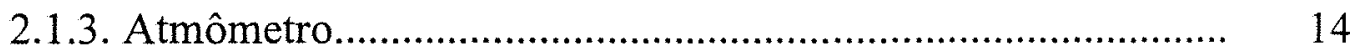

2.1.4. Umidade do Ar no Interior de Estufas.................................... 18

2.1.5. Temperatura do Ar e do Solo no Interior de Estufas .............. 19

2.2. Coeficiente de Cultura ...................................................................... 20 
Página

3. MATERIAL E MÉTODOS.................................................................. 23

3.1. Aspectos Gerais ...................................................................... 23

3.2. Localização Geográfica .................................................................. 23

3.3. Preparação dos Vasos ................................................................. 24

3.3.1. Descrição dos Vasos ............................................................ 24

3.3.2. Descrição do Substrato ....................................................... 24

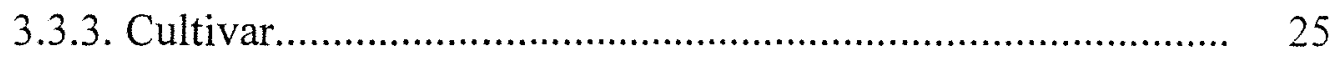

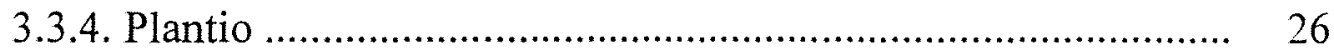

3.3.5. Irrigação ............................................................................. 26

3.4. Delineamento Experimental ........................................................... 27

3.4.1. Descrição da Forma de Condução da Cultura do Crisântemo e Número de Estádios

3.4.2. Número de Épocas do Ano ................................................. 27

3.5. Parâmetros a serem avaliados ....................................................... 28

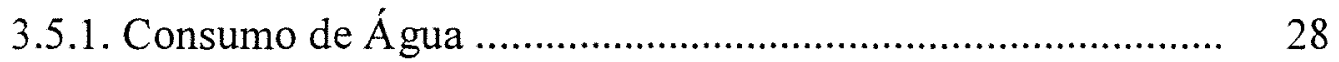

3.5.2. Área Foliar ........................................................................... 29

3.5.3. Parâmetros Climáticos ........................................................ 29

3.5.3.1. Evaporação ......................................................... $\quad 30$

3.6. Análise dos Resultados ............................................................... 32

4. RESULTADOS E DISCUSSÃO ............................................................. 34

4.1. Área Foliar em Função dos Dias após o Plantio das Mudas............. 34 
Página

4.2. Matéria Seca do Crisântemo............................................................... 37

4.3. Coeficiente de Consumo de Água pelo Crisântemo......................... 40

4.4. Consumo de Água pelo Crisântemo ............................................ 47

4.4.1. Consumo de Água pelo Crisântemo em Função da Área Foliar e da Evaporação do Tanque Classe A modificado.

4.2.2. Consumo de Água pelo Crisântemo em Função da Área Foliar e da Evaporação do Atmômetro com Escala de Leitura Ampliada........

5. CONCLUSÕES. 


\section{LISTA DE FIGURAS}

Página

Figura 1 - Vaso de barro com crisântemo ........................................................ 25

Figura 2 - Balança de precisão de $0,1 \mathrm{~g}$, usada durante as pesagens............... 31

Figura 3 - (a) Tanque reduzido e parafuso micrométrico sobre estrado de madeira, ladeado por vasos com grama. (b) Atmômetro de escala ampliada

Figura 4 - Representação da correlação entre área foliar e dias após plantio das mudas, envolvendo todos os dados coletados

Figura 5 - Dados medidos versus dados estimados pela equação polinomia raiz quadrada, da área foliar em função dos dias após o plantio da mudas, para todos os dados coletados.

Figura 6 - Matéria seca total do crisântemo em função dos dias após o plantio das mudas, para todos os dados coletados durante 0 experimento.

Figura 7 - Dados medidos versus dados estimados pela Equação 4, da matéria seca total do crisântemo em função dos dias após o plantio das mudas, para todos os dados coletados............................ 
Página

Figura 8 - Dados medidos versus dados estimados pela Equação 5, do coeficiente de consumo de água pelo crisântemo, em função dos dias após plantio das mudas, para todos os dados coletados.

Figura 9 - Representação da correlação entre o consumo de água pelo crisântemo adimensionalizado pelo máximo consumo diário da cultura e dias após o plantio das mudas, envolvendo todos os dados coletados

Figura 10 - Dados medidos versus dados estimados de consumo de água pelo crisântemo adimensionalizado pelo máximo consumo diário, envolvendo todos os dados coletados

Figura 11 - Dados medidos do consumo de água pelo crisântemo versus dados estimados a partir da área foliar e da evaporação do tanque reduzido, envolvendo todos os dados coletados

Figura 12 - Dados medidos do consumo de água pelo crisântemo versus dados estimados a partir da área foliar e da evaporação do atmômetro de escala ampliada, envolvendo todos os dados coletados. 


\section{LISTA DE TABELAS}

Página

Tabela 1 - Valor percentual de areia, silte, argila e matéria orgânica, e massa específica real do substrato utilizado no preenchimento dos vasos. 24

Tabela 2 - Calendário de avaliações do consumo de água pelo crisântemo...... 28

Tabela 3 - Épocas, número de observações $(N)$, coeficientes de regressão (a, b e c), coeficientes de correlação $\left(r^{2}\right)$ e índices de concordância (D), das equações da área foliar, em função dos dias após plantio da mudas.

Tabela 4 - Épocas, número de observações $(\mathrm{N})$, coeficientes de regressão (a, b e c), coeficientes de correlação $\left(r^{2}\right)$ e índice de concordância (D) das equações da matéria seca do crisântemo, em função dos dias

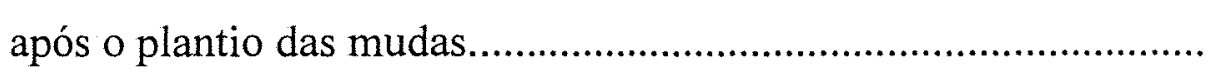

Tabela 5 - Épocas, número de observações $(\mathrm{N})$, coeficientes de regressão (a, b e c), coeficientes de correlação $\left(\mathrm{R}^{2}\right)$ e índice de concordância (D) das equações dos dias após o plantio das mudas, em função do coeficiente de consumo de água pelo crisântemo 
Página

Tabela 6 - Épocas, número de observações $(\mathrm{N})$, coeficientes de regressão (a, b e c), coeficientes de correlação $\left(R^{2}\right)$ e índice de concordância (D) das equações dos dias após o plantio das mudas, em função do consumo de água pelo crisântemo, adimensionalizado pelo máximo consumo diário

Tabela 7 - Épocas, número de observações $(N)$, coeficientes de regressão (a, b e c), coeficientes de correlação $\left(R^{2}\right)$ e índice de concordância (D) das equações do consumo de água pelo crisântemo, em função da área foliar e da evaporação do tanque reduzido

Tabela 8 - Épocas, número de observações $(\mathrm{N})$, coeficientes de regressão (a, b e c), coeficientes de correlação $\left(R^{2}\right)$ e índice de concordância (D) das equações do consumo de água pelo crisântemo, em função da área foliar e da evaporação do atmômetro de escala 51 ampliada 


\section{LISTA DE SÍMBOLOS}

a, b, c - Parâmetros de regressão;

$\mathrm{AF} \quad$ - Área foliar, $\mathrm{m}^{2}$;

ATM - Evaporação do atmômetro de escala ampliada, $\mathrm{mm} /$ dia;

$\mathrm{CA}$ - Consumo de água pelo crisântemo, $\mathrm{mm} / \mathrm{dia}$;

CC - Coeficiente de consumo de água pelo crisântemo;

CMA - Coeficiente de consumo de água pelo crisântemo adimensionalizado pelo máximo consumo diário;

CMX - Consumo de água do estádio de máximo consumo diário, $\mathrm{mm} / \mathrm{dia}$;

D - Índice de concordância de Willmott (1981);

DAP - Dias após o plantio das mudas;

ECA - Evaporação do tanque Classe A;

ETa - Evapotranspiração real;

ETc - Evapotranspiração da cultura;

ETm - Evapotranspiração máxima;

ETo - Evapotranspiração de referência relacionada com a grama batatais (Paspalum notatum L.); 
ETPenman Evapotranspiração de referência estimada pela equação de Penman (1956);

ETr - Evapotranspiração de referência relacionada com a alfafa (Medicago sativa L.);

f $\quad$ - Fator de correção de leitura do atmômetro de escala ampliada;

$\mathrm{K} \downarrow \quad$ - Densidade de fluxo de radiação global incidente medida;

$\mathrm{Ka}$ - Coeficiente de cultura da alfafa;

Ke $\downarrow$ - Densidade de fluxo de radiação global incidente estimada;

MS - Matéria seca total do crisântemo, g;

$\mathrm{N}$ - Número de observações;

$\overline{\mathrm{O}} \quad$ - Valor medido médio, $\mathrm{mm} / \mathrm{dia}$;

Oi - Valores medidos de consumo de água pelo crisântemo, $\mathrm{mm} / \mathrm{dia}$;

$\overrightarrow{\mathbf{P}} \quad$ - Valor previsto médio, $\mathrm{mm} / \mathrm{dia}$;

PEDB - Polietileno de baixa densidade;

$\mathrm{Pi} \quad$ - Valores previstos de consumo de água pelo crisântemo, $\mathrm{mm} / \mathrm{dia}$;

$\mathrm{R}^{2} \quad$ - Coeficiente de determinação para equação de regressão múltipla;

$r^{2} \quad$ - Coeficiente de determinação para equação de regressão simples;

Rd - Radiação difusa;

Rs - Radiação total;

TR - Evaporação do tanque reduzido, $\mathrm{mm} /$ dia. 


\title{
CONSUMO dE ÁGUA PELA CULTURA dO CRISÂNTEMO ENVASADO, CULTIVAR PURITAN, SOB CONDIÇÕES DE ESTUFA
}

\author{
Autora: RAQUEL APARECIDA FURLAN \\ Orientador: PROF. DR. TARLEI ARRIEL BOTREL
}

\section{RESUMO}

A programação de projetos de irrigação, em geral implica em estudar muitas variáveis, muitas das quais se oferecem a uma particularização, tal como se fez com o presente trabalho.

O objetivo principal desta pesquisa foi avaliar o consumo de água pelo crisântemo (Dendrantema grandiflora cv. Puritan), cultivado em vasos mantidos em estufa, através da comparação do peso desses vasos, em diferentes estádios de desenvolvimento da planta, com: a) o peso de idênticos vasos contendo grama batatais de mesma idade, e cultivada com práticas culturais semelhantes; b) a evaporação de um tanque reduzido; c) a evaporação de um atmômetro com escala de leitura ampliada; d) a área foliar da planta, no estádio de desenvolvimento considerado.

As investigações foram conduzidas na propriedade Granja Triângulo, município Holambra - SP, em cultivos rotineiramente desenvolvidos pelo produtor, buscando a melhor representatividade dos dados obtidos.

Para maior abrangência das condições climáticas, foram realizadas determinações em agosto, outubro e dezembro de 1995, e em fevereiro, abril e 
junho de 1996, coletando dados de plantas com cinco idades diferentes, intervaladas a cada duas semanas. Em cada estádio foram avaliadas as plantas contidas em cinco vasos, perfazendo, portanto, cinco repetições.

Foram também ajustadas equações de regressão múltipla do consumo de água do crisântemo em função: a) da área foliar do crisântemo e da evaporação do tanque reduzido; b) da área foliar do crisântemo e da evaporação do atmômetro com escala de leitura ampliada.

Com os resultados obtidos evidenciou-se que: a) há correlação entre os dados medidos e os estimados pela regressão, tanto por período de coletas de dados, como para o conjunto de dados experimentais; b) o consumo de água pelo crisântemo, nestas condições de estufa, pode ser estimado pela evaporação de água do tanque reduzido ou pela evaporação do atmômetro com escala de leitura ampliada, através das equações de regressão múltipla, desde que seja conhecida a área foliar da planta, no estádio de desenvolvimento considerado e pode ser estimado a partir dos dias após o plantio das mudas e do consumo de água do estádio de máximo consumo diário. 


\title{
WATER CONSUPTION RATES BY POTTED CHRYSANTHEMUM, CULTIVAR PURITAN, UNDER GREENHOUSE CONDITIONS
}

\author{
Author: RAQUEL APARECIDA FURLAN \\ Adviser: PROF. DR. TARLEI ARRIEL BOTREL
}

\section{SUMMARY}

One of the several variables considered in the design of an irrigation system is the maximum water requirement of the crop that will be irrigated. The main objective of this work was to evaluate the evapotranspiration rate of the chrysanthemum (Dendrantema grandiflora cv. Puritan) under greenhouse conditions and tillage practices adopted by a traditional producer of flowers (Granja Triângulo) located in Holambra county, SP - Brazil.

By comparing chrysanthemum pots weight during different stages of growth and development with a) grass pots weights, b) evaporation of a modified class A pan, c) evaporation of a modified atmometer and d) the leaf area index, it was possible to estimate the water requirement of this crop.

The experiment was conducted from August to December - 95 and from February to June - 96, evaluating five different stages of growth and development, on a two-week data acquisition base, with five pots (repetition) per treatment. Multiple regression curves of the chrysanthemum evapotranspiration 
rate with leaf area index, evaporation of a modified class $\mathrm{A}$ pan and evaporation of a modified atmometer were obtained.

The study allow us to conclude that: a) there was statistical correlation between measured data and estimated data (multiple regression curves) and b) chrysanthemum evapotranspiration rates can be estimated, using modified class A pan and modified atmometer readings, considering the leaf area index of the growth stage considered. 


\section{INTRODUÇÃO}

A produção comercial de plantas ornamentais exerce importantes funções sociais, culturais e ecológicas. Como atividade agrícola intensiva, valoriza a mão-de-obra no campo, explorando pequenas áreas com alto retorno. A floricultura, no aspecto cultural e ecológico, salienta não só o uso de flores para ornamentação de cerimônias cívicas, civis ou religiosas mas, também, a preservação e divulgação de espécies nativas em extinção nos seus habitates (Kampf, 1989).

Dentre as flores cultivadas em vasos, destaca-se o crisântemo (Dendranthema grandiflora Tzvelev.) que é uma planta ornamental comercializada em todo o mundo pela beleza de sua inflorescência.

As variedades de crisântemo apresentam uma porcentagem expressiva na demanda mundial de flores de corte e envasadas, ocupando cerca de $12 \%$ do mercado holandês de flores cortadas e $34 \%$ do mesmo mercado para flores envasadas (Kampf et al. 1990). De acordo com o artigo Mercado..., em 1987 esta planta ornamental já se encontrava entre as flores com o maior volume das exportações brasileiras, dirigido, principalmente, para o mercado europeu.

Por ser uma cultura de grande valor comercial, de alta tecnologia de produção e exigente em fotoperiodismo, sua produção é conduzida, geralmente, em ambientes protegidos, de maneira a fornecer flores ao mercado, durante o ano todo. 
A plasticultura, é uma técnica nova no Brasil e poucas pesquisas têm sido realizadas no sentido de se determinar, com maior precisão, o consumo de água pelas culturas desenvolvidas no interior de estufas plásticas.

O consumo de água pelo crisântemo, e das plantas ornamentais é, no geral, pouco estudado, sendo a literatura a respeito praticamente inexistente. Desse modo, nota-se que há uma certa dificuldade por parte dos produtores em se fazer o manejo racional da irrigação nessas culturas, principalmente naquelas conduzidas em ambiente protegido, visto que, por apresentarem condições ambientais próprias, impedem o uso direto dos métodos, já consagrados, para a determinação da evapotranspiração. Certos autores, como Montero et al. (1985) e Rosenberg et al. (1989), afirmam que a evapotranspiração no interior das estufas corresponde de $60 \%$ a $80 \%$ da verificada exteriormente.

Nesse contexto, o presente trabalho teve por objetivo determinar o consumo de água pelo crisântemo, cultivado em vasos mantidos em ambiente protegido, através da comparação de seus pesos, em diferentes fases do desenvolvimento da planta com: 


\section{REVISÃO DE LITERATURA.}

O crisântemo é uma planta originária do Japão, tendo sido introduzida no Ocidente há, aproximadamente, 200 anos. (Barbosa \& Martinez, s/d). Do Japão penetrou na China, onde passou a ser cultivado. No século XVI foi introduzido na Europa, seguindo sua trajetória para a África do Norte, atingindo mais tarde as Américas (Cavalcante, 1994).

Chegou ao Brasil há pouco mais de 50 anos, entrando pela Argentina e Uruguai e, posteriormente, ganhou aperfeiçoamento com a introdução de novas espécies e variedades vindas dos Estados Unidos, Holanda e Japão (Yanagisawa, 1992). Depois da rosa é a flor mais cultivada no país, com a maior parte da produção concentrando-se em São Paulo.

No Estado de São Paulo, existem dois mercados onde se comercializam flores e plantas ornamentais: CEAGESP-SP (Companhia de Entrepostos e Armazéns Gerais de São Paulo) e a Cooperativa Agropecuária Holambra (Veiling Holambra).

De acordo com ${ }^{1}$ Optiz (1996) cerca de 30\% de toda operação de venda de crisântemo de vaso para o mercado interno é feita através do Veiling Holambra. Em 1995 foram comercializados 1.164.675 vasos e a previsão de comercialização até o final de 1996 é de aproximadamente 1.420 .333 vasos de crisântemo.

${ }^{1}$ OPTIZ, R. (Veiling Holambra). Informação pessoal, 1996. 
Atualmente tem crescido muito a quantia de mudas de crisântemo exportadas pelo Brasil para países como Holanda, Japão, Inglaterra e alguns países do Mercosul. Segundo ${ }^{2}$ Bandeira (1996) a Schoenmaker van Zanten, maior produtor de mudas de crisântemos dentro do Brasil para exportação e mercado interno, produz cerca de 150.000 .000 de mudas anuais somente para exportação.

O crisântemo pertence à familia Asteraceae. São plantas de fotoperiodicidade negativa e, por isso, as noites longas estimulam a formação e desenvolvimento dos botões.

\subsection{EVAPOTRANSPIRAÇÃO}

O termo evapotranspiração potencial (ETp) foi introduzido na literatura por Thornthwaite (1948), definindo-a como sendo a quantidade máxima de água utilizada por uma extensa área vegetada, em crescimento ativo, sob condições ótimas de umidade do solo.

Quando as condições de contorno acima não forem verificadas, temse a evapotranspiração real (ETa), que é aquela que ocorre em uma superfície vegetada, independente de sua área e das condições de umidade do solo (Thornthwaite, 1948; Sediyama, 1987; Villa Nova \& Reichardt, 1989 e Pereira, 1994).

Doorenbos \& Pruitt (1977), introduziram o conceito de evapotranspiração da cultura (ETc), caracterizando-a como sendo a evapotranspiração de uma cultura agronômica, livre de doenças, desenvolvendose em uma área cultivada de um ou mais hectares, sob condições otimizadas de

${ }^{2}$ BANDEIRA, S. F. (Schoenmaker van Zanten). Informação pessoal, 1996. 
solo, incluindo água e fertilidade. O conhecimento de ETc é fundamental em projetos de irrigação, pois representa a quantidade de água que deve ser reposta ao solo, para manter o crescimento e a produção em condições ideais. No entanto, a determinação de ETc é dificil e sujeita a muitos erros (Pereira, 1994).

Segundo Peres (1994), encontram-se na literatura duas definições mais comuns para evapotranspiração de referência: uma relacionada com a cultura de referência grama (ETo) e outra com a cultura de referência alfafa (ETr).

Segundo Doorenbos \& Pruitt (1977), evapotranspiração de referência é aquela de uma extensa superfície de grama batatais (Paspalum notatum L.) com altura de 8 a $15 \mathrm{~cm}$, em crescimento ativo, cobrindo totalmente o solo e sem deficiência de água.

Jensen (1973), definiu ETr como sendo o limite superior ou a evapotranspiração máxima que ocorre numa cultura de alfafa (Medicago sativa L.), com altura de 30 a $50 \mathrm{~cm}$, numa dada condição climática e com, aproximadamente, $100 \mathrm{~m}^{2}$ de área tampão, cultivada sem deficiência hídrica.

Embora se reconheça que a alfafa possua características aerodinâmicas mais representativas da maioria das culturas agronômicas do que a grama, esta última é mais utilizada pelo simples fato de a grande maioria das estações agrometeorológicas serem gramadas (Jensen, 1973 e Smith, 1991). O outro ponto favorável à grama é que ela se adapta mais facilmente a diferentes condições climáticas do que a alfafa (Peres, 1994 e Pereira, 1994).

Doorenbos \& Kassam (1979) apresentaram o termo evapotranspiração máxima (ETm ), e o definiram como sendo a transferência de água para a atmosfera por uma superficie onde a cultura vegetal é uma cultura agronômica, em qualquer estádio de seu desenvolvimento, em condições ideais de umidade do solo e de manejo agronômico. 
Vários são os fatores que podem interferir na evapotranspiração das culturas. Pruitt et al. (1972), verificaram que a abertura dos estômatos, a refletância, a rugosidade aerodinâmica, bem como a extensão da área coberta pelo vegetal e a estação do ano, são fatores significativos no processo. Burman et al. (1980); Sediyama (1987) e Bernardo (1989), comentam que a quantidade de água evapotranspirada depende, principalmente, da planta, do solo e do clima, sendo que este último fator predomina sobre os demais. As condições de solo e sua umidade, os fertilizantes, as infestações de pragas e doenças, as práticas agrícolas e a irrigação são citados por Doorenbos \& Pruitt (1977), como fatores que podem também influenciar nas taxas de crescimento da cultura e, consequentemente, na evapotranspiração.

De acordo com Farias et al. (1994), as coberturas plásticas criam condições bastante diferentes daquelas encontradas a céu aberto e são impermeáveis aos líquidos, impedindo a entrada da água da chuva, tornando-se extremamente importante um melhor conhecimento das exigências hídricas das plantas no interior de estufas uma vez que a irrigação será, na grande maioria das vezes, a única forma de suprimento de água às culturas. As estufas afetam alguns elementos meteorológicos muito importantes ao desenvolvimento das plantas, como temperatura, umidade relativa do ar e radiação.

No interior da estufa, a evapotranspiração é, em geral, menor do que a verificada externamente, o que atribui-se, basicamente, à parcial opacidade da cobertura plástica à radiação solar e à redução da ação dos ventos, que são os principais fatores da demanda evaporativa da atmosfera, embora a temperatura do ar e a umidade relativa, em alguns momentos, possam ser respectivamente, maior e menor no interior da estufa do que a céu aberto, o que contribuiria para maior evapotranspiração. A diferença entre a evapotranspiração interna e externa varia de acordo com as condições meteorológicas; em geral, a evapotranspiração no 
interior fica em torno de 60-80\% da verificada no exterior $\left({ }^{3}\right.$ Van der Post et al., 1974; ${ }^{4}$ Prados, 1986, citados por Farias et al., 1994; Rosenberg et al., 1989 e Montero et al., 1985).

Atualmente, muitos são os métodos propostos para quantificar-se a evapotranspiração fora de estufas, mediante a utilização de equipamentos instalados em condições de campo ou com o emprego de modelos teóricos que consideram elementos do clima, solo e planta.

Os métodos de determinação da evapotranspiração foram revistos por Burman et al. (1980), que sugeriram classificá-los em dois grandes grupos: o grupo de medidas diretas e o grupo de medidas indiretas.

Os métodos de medidas diretas ou métodos do balanço hídrico podem ser divididos basicamente em dois tipos: os que utilizam lisímetros e aqueles em que a estimativa é feita diretamente num volume controlado de solo (balanço hídrico sob condições de campo).

Os métodos de medidas indiretas ou os métodos de estimativas determinam a evapotranspiração a partir de fórmulas empíricas, semi-empíricas e evaporimetros. A opção por um ou outro método dependerá, na maioria das vezes, da precisão requerida ou do tipo de dado climatológico disponível, uma vez que nenhum do métodos propostos parece desfrutar de preferência absoluta.

Doorenbos \& Pruitt (1977), apresentaram 31 métodos para a estimativa da evapotranspiração, mostrando o grande número de métodos existentes. Sedyama (1987) comenta a existência de cerca de 50 métodos. Para

3 VAN DER POST, C. J.; VAN-SHIE, J. J.; GRAAF, R. Basic problems of water relationship: energy balance and water supply in glasshouses in the West-Netherlands. Acta Horticulture. The Hague, v.35, p.13-21. 1974.

4 PRADOS, N. C. Contribución al estudio de los cultivos enarenados en Almeria: Necessidades hídricas y extracion del nutrientes del cultivo de tomate de crescimento indeterminado en abrigo de polietileno. Tesis Doctoral. Almeria, Espana. 1986. 195p. 
este autor, estes métodos podem ser divididos em quatro classes: $1^{\circ}$ ) os métodos que tem como base a temperatura, dentre estes destacam-se o de Thornthwaite e Blaney-Criddle; $2^{\circ}$ ) os métodos baseados em temperatura e radiação, destacando o de Jensen-Haise, a equação de Makkink modificada pela FAO e a equação de Hargreaves; $3^{\circ}$ ) os métodos combinados que compreendem o fato de que as equações propostas associam os efeitos do balanço de energia à superfície e os termos de energia convectiva para estimar as perdas de água de superfícies cultivadas, sendo a equação de Penman a mais conhecida entre os pesquisadores e, finalmente, $4^{\circ}$ ) os métodos de evaporação em tanques, onde os tanques USWB (United State Weather Bureau) e Classe A são os mais utilizados.

Avaliações feitas por Doorenbos \& Pruitt (1977) apresentam como melhor método de estimativa da evapotranspiração de referência o método de Penman modificado, com erros ao redor de $10 \%$ no verão e até $20 \%$, sob condições de baixa demanda evaporativa.

As diferenças encontradas nos resultados pelos diversos métodos, quando utilizados em diferentes regiões, tem sido motivo de preocupação para os pesquisadores, que têm desenvolvido estudos visando avaliar e ajustar as relações existentes (Silva, 1989).

De acordo com ${ }^{4}$ Prados (1986), citado por Farias et al. (1994), no estudo da evapotranspiração em estufas, são poucos os trabalhos que têm medido a evapotranspiração de referência de acordo com a definição de Doorenbos \& Pruitt (1977) para estimar o consumo de água das culturas. Lisímetros cultivados com gramíneas (em geral, com Festuca sp) tem sido usados em estudos de evapotranspiração no interior de estufas plásticas, e diferentes tipos de evaporímetros têm sido empregados na estimativa da evapotranspiração em estufas. Este mesmo autor também concluiu que, para estufas, o método do 
tanque evaporimétrico com coeficientes de tanque $(\mathrm{Kp})$ iguais a 1.0 , juntamente com os métodos da radiação solar (FAO) e de Priestley-Taylor, são os melhores para estimar a evapotranspiração de referência no interior de estufas.

Segundo Montero \& Antón (1994), a transpiração de culturas pode ser estimada por diferentes métodos. Uma aproximação é a medida da perda de peso das plantas e o uso de uma análise de regressão para correlacionar este com outras variáveis ambientais.

Jolliet \& Bailey (1992), usaram este método para determinar a transpiração de plantas sobre uma balança em um túnel de vento e encontraram que a transpiração cresce linearmente, em casa de vegetação, com a radiação solar incidente, déficit de pressão de vapor e velocidade do vento.

${ }^{5}$ Bailey et al. (1992), citado por Montero \& Antón (1994), desenvolveram uma regressão para determinação da transpiração em Ficus benjamina em casa de vegetação, que relaciona a radiação global e é especifica para um índice de área foliar e portanto aplicado somente em casos muito particulares.

\subsubsection{RADIAÇÃO SOLAR NO INTERIOR DE ESTUFAS}

A densidade de fluxo de radiação solar no interior da estufa é menor que a verificada externamente, devido a reflexão e à absorção pelo material da cobertura plástica (Martin et al., 1982).

O material plástico mais empregado atualmente na agricultura, em nível mundial, é o polietileno de baixa densidade (PEBD). O PEBD é um

5 BAILEY, J., JOLLIET, O., WILKINSON, D. J., MONTERO, J. I. , ANTÓN, A. , BIEL, C. Transpiration of Ficus benjamina: Comparison of measurements with predictions of three models. 1992. 
material que apresenta boa transparência à radiação solar, deixando passar, em média, 70 a $80 \%$ da radiação solar, podendo este percentual atingir no máximo, 95\% (Martin \& Robledo, 1981).

Reiser Junior et al. (1991), trabalhando com estimativa de evapotranspiração máxima (ETm) em cultura de alface, cv BR-221, dentro e fora de estufa, estimou ETm em função da densidade de fluxo de radiação global incidente medida $(\mathrm{K} \downarrow)$, e estimada (Ke $\downarrow$ ). A ETm foi determinada utilizando-se microlisímetros instalados dentro e fora da estufa, através de pesagem, e a energia solar na parte externa medida por actnógrafo e, ainda, estimada por equações propostas por Estefanel et al. (1990). A análise de regressão dos dados mostra as seguintes equações, dentro da estufa: $\mathrm{ETm}=0.63+4.2356 * \mathrm{~K} \downarrow\left(\mathrm{r}^{2}=0.74\right)$; $\mathrm{ETm}=0.98+4.8487 * \operatorname{Ke} \downarrow\left(\mathrm{r}^{2}=0.72\right) ;$ fora da estufa, ETm $=0.47+5.7411 *$ $\mathrm{K} \downarrow \quad\left(\mathrm{r}^{2}=0.64\right) ; \quad \mathrm{ETm}=0.98+7.2788 * \mathrm{Ke} \downarrow \quad\left(\mathrm{r}^{2}=0.75\right) . \quad$ Os valores de coeficiente de determinação foram baixos, e permitem inferir que não é possível estimar ETm, com precisão satisfatória em função da radiação solar global incidente fora da estufa.

Robledo De Pedro (1987), comparando vários tipos de plásticos, verificou uma diminuição média variando de 10 a $17 \%$ na transmissividade, enquanto que Farias et al. (1993a), utilizando polietileno de baixa densidade (PEBD), verificaram uma redução de 10 a $35 \%$ na transmissividade, no intervalo de 11 à 13 horas, e de 17\%, em média, ao longo do dia. Montero et al. (1985) e Mills et al. (1990), também encontraram resultados que muito se aproximam destas observações.

Medindo a radiação solar global no interior de uma estufa coberta com PEDB, Al-Riahi et al. (1989), observaram um aumento na transmissividade devido a uma menor condensação na cobertura plástica e principalmente devido 
ao aumento do azimute do sol, caracterizando assim uma variação temporal da transmissividade.

De uma maneira geral, pode-se dizer que a quantidade de energia solar não transmitida é devido ao tipo de cobertura e ao ângulo de incidência dos raios solares, o que é condicionado pela orientação da estufa, pela inclinação do telhado e posição do sol (Robledo De Pedro \& Vicente, 1988 e Hanan et al., 1978).

Contudo, embora exista uma redução da radiação solar global no interior da estufa, Farias et al. (1993a), encontraram um maior valor da razão entre radiação difusa e total ( $\mathrm{Rd} / \mathrm{Rs}$ ) dentro da estufa, sendo este fator muito importante, pois a radiação difusa é multidirecional podendo ser melhor aproveitada pelas plantas. Esta relação de $\mathrm{Rd} / \mathrm{Rs}$, pode variar bastante entre os diferentes tipos de plásticos, variando de $15 \%$ para polietileno normal (sem aditivo), até 65\% em alguns materiais (Robledo De Pedro, 1987).

Pezzopane (1994), utilizando estufa coberta com polietileno transparente de baixa densidade (PEBD) na produção de mudas de seringueira, verificou que no interior da estufa a radiação solar global foi reduzida, a radiação líquida noturna foi menos negativa, ocorrendo um aumento, em algumas horas do dia, na pressão atual de vapor e umidade relativa e resultando em redução do déficit de pressão de vapor; também verificou elevação da temperatura do solo e das folhas.

\subsubsection{TANQUE CLASSE A}

Teodoro (1986), estudando a influência da irrigação por gotejamento dentro e fora de casa-de-vegetação na produção de pimentão 
(Capsicum annuum L.), obteve uma média diária de evaporação medida no Tanque Classe A de $4.6 \mathrm{~mm} / \mathrm{dia}$, dentro da casa de vegetação e $5.6 \mathrm{~mm} / \mathrm{dia}$ em condições de campo.

Santos (1986), também estudando a influência da irrigação por gotejamento dentro e fora de casa-de-vegetação na produção de tomate (Lycopersicon esculentun Mill), obteve os seguintes valores de evaporação: condições de campo: novembro 6.18; dezembro 6.30; janeiro 4.37 e fevereiro 3.59; casa-de-vegetação: novembro 4.84; dezembro 4.69; janeiro 5.50 e fevereiro 3.38 (valores $\mathrm{mm} / \mathrm{dia}$ ). Exceto o mês de janeiro, todos os meses nos quais foi desenvolvido o experimento, apresentaram valores maiores de evaporação em condições de campo. Isto em parte pode ser explicado, quando se observa os totais pluviométricos que, para o mês de janeiro, esteve na faixa de $133.2 \mathrm{~mm}$, enquanto que os demais meses mantiveram-se na faixa de $40 \%$ a menos deste total. Assim sendo, toda a quantidade de água precipitada é retirada do tanque, uma vez que o parafuso micrométrico é de difícil calibração, podendo estar embutido nestas leituras erros de medidas, justificando os maiores valores de evaporação dentro da casa-de-vegetação.

Martins (1992), em estudos relacionados com casa de vegetação com cobertura plástica, visando caracterizar seu efeito em culturas de tomateiro de verão, encontrou, em média, valores de evaporação medidos em casa-devegetação da ordem de $78 \%$ daquele medido externamente. Para este autor, esta diferença é explicada tendo em vista que tanque Classe $\mathrm{A}$ integra o efeito da radiação solar, do vento, da temperatura e da umidade relativa do ar, sendo que, em condições de campo, a circulação do ar (vento) não encontra obstáculos, uma vez que, pelas normas estabelecidas pela O.M.M. (Organização Meteorológica Mundial), a superfície onde está instalada uma estação meteorológica, deve ser coberta de grama com baixo porte. Por outro lado, em condição de estufa, a 
velocidade do vento é praticamente zero e o balanço de energia também é reduzido, em função das propriedades de absorção e reflexão da cobertura plástica. Analisando os valores de consumo de água dentro e fora da estufa e, também, o coeficiente de tanque e o coeficiente de cultura igual a 1.0, nota-se que o consumo de água pela cultura na estufa foi, em média, $31 \%$ menor, quando comparados com valores medidos externamente.

${ }^{4}$ Prados (1986), citado por Farias et al. (1994), comparando os valores de evaporação em tanque Classe A, ocorridos no interior e no exterior da estufa, obteve correlação de 0.38 e 0.86 , para períodos semanais de baixa e alta demanda evaporativa, respectivamente, e 0.96 para períodos de duas semanas.

Pelúzio (1992) conduziu experimento nas condições edafoclimáticas de Viçosa (MG), para avaliar seis níveis de água aplicados com base na evaporação do Tanque Classe A $(0.4,0.6,0.8,1.0,1.2$ e 1.4$)$, em alface e, utilizando um sistema de irrigação por gotejamento, verificou que os níveis de água influenciaram de maneira crescente o número de folhas, área foliar, matéria fresca e seca da parte aérea das plantas. A eficiência do uso de água (medida como relação entre a produção de matéria seca total e a quantidade total de água aplicada) aumenta à medida que cresce o nível de água aplicado, sendo que a eficiência máxima foi obtida com a aplicação do nível 1.4 da evaporação do Tanque Classe A.

Andrade Júnior (1994) avaliou o efeito de diferentes níveis de irrigação baseados em frações $(0.25,0.50,0.75$ e 1.00) da evaporação do Tanque Classe A (ECA), sobre o comportamento fisiológico e produtivo da cultura da alface (Lactuca sativa L.), cultivada em uma estufa plástica e irrigada por gotejamento. O comportamento da cultura foi avaliado através de parâmetros de crescimento (número de folhas, área foliar e matéria seca), índices fisiológicos [Taxa de Crescimento da Cultura (TCC), Taxa de Crescimento Relativo (TCR), 
Taxa Assimilatória Líquida (TAL) e Índice de Área Foliar (IAF)], matéria fresca, produtividade e eficiência do uso da água. Verificou que os melhores resultados de número de folhas, área foliar (IAF) e matéria seca foram obtidos com nível 0.75 da ECA. Em termos de produção, o nível 0.75 da ECA proporcionou as maiores médias de matéria fresca e produtividade. Entretanto, o melhor índice de eficiência do uso de água foi obtido com o nível 0.50 da ECA.

Farias et al. (1994) compararam as evapotranspirações dentro e fora da estufa plástica, através de um experimento conduzido no campus da Universidade Federal de Pelotas, de setembro/89 a janeiro/90, em estufa plástica, com área de $500 \mathrm{~m}^{2}$, revestida com polietileno de baixa densidade, de $0.1 \mathrm{~mm}$ de espessura e transmissividade média à radiação solar global de $83 \%$. A evapotranspiração de referência para grama (ETo) foi estimada pelo método de Penman (1956) e a partir de medidas de evaporação em tanque Classe A e em um tanque reduzido (diâmetro interno de $0.2 \mathrm{~m}$ e altura de $0.25 \mathrm{~m}$ ). Os maiores valores de ETo foram obtidos pelo método Penman e os menores pelo tanque Classe A. Comparando os resultados obtidos entre os dois ambientes, verificou-se que a ETo interna foi sempre menor, ficando entre $45 \%$ e $77 \%$ da verificada na parte externa. As estimativas de ETo interna, a partir do tanque reduzido, apresentaram elevadas correlações com as obtidas pelo tanque Classe A ( $r$ de 0.84 a 0.90 ).

\subsubsection{ATMÔMETRO}

Com intuito de facilitar a quantificação da ETo, a nível de campo, Altenhofen (1985) desenvolveu um aparelho para determinar a evapotranspiração de referência, na propriedade agrícola, buscando precisão, simplicidade de utilização e boa aceitação pelos irrigantes. 
$\mathrm{O}$ atmômetro modificado de Altenhofen é uma modificação do atmômetro de Bellani, usado para medir evaporação. Consiste de uma cápsula porosa (cerâmica de Bellani), envolvida por uma lona verde e grossa, montada horizontalmente na parte de cima de um reservatório cilíndrico. A água destilada é fornecida à cerâmica, pela parte inferior do reservatório, através de um tubo de sucção. Uma pequena válvula é instalada na parte final do conduto para evitar a entrada de chuva ou de água de irrigação desde o meio externo. Uma pequena abertura permite a entrada de ar para manter a pressão atmosférica dentro do reservatório de água. O nível da água no reservatório é visualizada através de um tubo plástico transparente localizado lateralmente ao eixo principal do atmômetro (National..., 1985).

Segundo Altenhofen (1985), a simulação da transpiração das plantas é atingida, cobrindo-se a superfície de evaporação (cápsula de Bellani) com a lona verde. A cobertura com a lona verde tem dois objetivos: o primeiro é simular o albedo do cultivo a partir da absorção de radiação solar das plantas; o segundo é simular a resistência à difusão da folha ao fluxo de vapor de água, desde o interior da folha até a atmosfera.

De acordo com Law (1990) e Broner (1990), os procedimentos adequados para a instalação e operação do atmômetro modificado são: 1) colocar o aparelho em posição vertical, com a extremidade da cerâmica a cerca de $1,0 \mathrm{~m}$ da superfície do solo; 2) o atmômetro deve ser instalado em local de fácil acesso, próximo ao campo irrigado; 3) o local deve ser representativo das médias das condições de campo; 4) o atmômetro não deve ser instalado perto de barreiras de vento ou insolação, tais como construções, árvores ou culturas altas; 5) conservar a lona verde limpa, lavando-a periodicamente; 6) instalação de uma bandeirola em. um poste alto, próximo do aparelho, para que pássaros não pousem no mesmo; 7) deve manter-se a continuidade da água através da cerâmica e do tubo de sucção, eliminando-se totalmente as bolhas de ar; 8) quando o nível de água do reservatório 
cair a, aproximadamente, dois terços, deve-se completar o nível novamente; 9) maior segurança e precisão de leitura podem ser obtidas, instalando-se mais de um aparelho no mesmo local; 10) no caso de diferenças significativas na leitura entre os instrumentos, as cerâmicas devem ser limpas e verificadas ou o fabricante contactado.

Blume et al. (1988) indicam a instalação do atmômetro a cerca de $1 \mathrm{~m}$ da superfície do solo, mas comentam que a altura ótima do atmômetro deveria ser a altura da cultura mas que isso requereria mover o atmômetro conforme $o$ crescimento da mesma.

Law \& Israeli (1988), também citados em Broner (1990) e Law (1990), realizaram, no centro de pesquisas de Engenharia Agrícola da Universidade do Colorado-EUA, um estudo visando verificar teórica e empiricamente, a aptidão do atmômetro modificado em estimar a evapotranspiração de referência da alfafa. O estudo teórico mostrou que o albedo da cultura e a resistência ao fluxo de vapor d'agua são satisfatoriamente simulados, cobrindo-se a cápsula porosa com a lona especial de cor verde. A condutividade hidráulica da cápsula não limitou a evaporação sob condições de alta demanda evaporativa e a quantidade de vapor d'agua, concentrada entre a lona e a cápsula, era praticamente idêntica àquela encontrada nas cavidades estomatais das folhas da alfafa. Em uma segunda etapa do estudo, a evapotranspiração estimada por quatro atmômetros foi comparada ao método de Penman. Os resultados obtidos mostraram que a variação entre os atmômetros instalados juntos uns aos outros foi pequena e que a evapotranspiração estimada pelo atmômetro modificado e pelo método de Penman foram similares. A variabilidade entre os aparelhos em periodos chuvosos foi grande e essa variabilidade pode ser devida, principalmente, ao mal funcionamento das válvulas de retenção dos atmômetros. Esses resultados foram preliminarmente favoráveis, já que a comparação foi limitada a um curto período de tempo (trinta dias). 
Blume et al. (1988) realizaram um experimento em condições de campo em Garden City, Kansas - EUA, envolvendo diversos métodos de medida de umidade do solo e consumo de água pelas plantas. A evapotranspiração do atmômetro e a evapotranspiração por Penman foram comparadas através de leituras acumuladas de 6 dias, a variabilidade entre os dois métodos foi pequena e o atmômetro apresentou um desempenho satisfatório.

Broner (1990) e Law (1990) citam um trabalho desenvolvido pelo Northern Colorado Water Conservation District, onde cálculos diários de evapotranspiração por Penman e evaporação do atmômetro foram coletados em estações meteorológicas automatizadas. Foram feitas observações nos verões de 1988 e 1989 para Loveland, Colorado e no verão de 1989 para Fort Collins, Colorado. Os dados de evapotranspiração foram analisados e comparados em médias diárias cumulativas e em períodos de sete dias acumulados. Os resultados obtidos mostraram que a diferença média diária ficou entre $5.6 \%$ e $16.4 \%$ para Loveland e entre $6.3 \%$ e $25 \%$ para Fort Collins. A diferença média acumulativa para o período de sete dias, ficou entre 0 e $14.8 \%$ para Loveland e entre $1.8 \%$ e 17.6\% para Fort Collins. Law (1990) e Broner (1990) citam que esses dados convergem para os resultados obtidos por Law e Israeli (1988). Os dados de Loveland - EUA, no verão de 1988, indicam que o atmômetro modificado pode ser utilizado como instrumento para estimar a evapotranspiração de referência da alfafa, para o proposto manejo da irrigação. Todavia, é recomendado, periodicamente, comparar a evapotranspiração estimada pelo atmômetro com outros métodos para assegurar a precisão do aparelho.

Pereira \& Coelho (1992) conduziram um experimento em condições de campo nas dependências do Departamento de Engenharia Rural da ESALQ/USP (Piracicaba - SP), visando avaliar o comportamento de um atmômetro modificado em condições tropicais, comparando a evaporação do atmômetro com a evapotranspiração de referência estimada pela equação de Penman (referência 
alfafa), durante os meses de abril a outubro de 1991. Obtiveram um coeficiente Ka, definido como a relação entre ET Penman e a evaporação do atmômetro, em torno de 1.04 , com coeficiente de variação de $18 \%$ para ETo entre 2.0 e $6.5 \mathrm{~mm} / \mathrm{dia}$. Desse experimento os autores concluíram que, em condições tropicais, o atmômetro modificado subestima a evapotranspiração de referência em torno de 4\%. Citam também que uma possível variabilidade da evaporação do atmômetro comparada à evapotranspiração obtida pela equação de Penman, pode ser devida à precisão limitada no aparelho $(0,5 \mathrm{~mm})$. A variabilidade, em dias chuvosos, deve-se à entrada de água no reservatório, tornando os dados coletados nesses dias, inconsistentes.

Bastos et al. (1993) utilizaram, na EMBRAPA/CPATU em Belém, para estimar a evaporação em áreas muito chuvosas na Amazônia o atmômetro Ekern, desenvolvido para medir evaporação em áreas de dificil acesso e intensa precipitação, no Hawaii - USA. O aparelho consiste de uma superfície evaporante constituída de pedra de filtro de $152 \mathrm{~mm}$ de diâmetro inserida em tubo de PVC que serve de reservatório de água e de proteção, e é coberto com uma peça de "plexiglass" branca de $3 \mathrm{~mm}$ de espessura e $0,1 \mathrm{~m}^{2}$ de área, instalada a $100 \mathrm{~mm}$ sobre a superficie evaporante. $\mathrm{O}$ atmômetro foi montado a $1,10 \mathrm{~m}$ de altura em uma área padrão gramada do posto agrometeorológico do CPATU. Os resultados obtidos, embora preliminares, mostraram concordância com os valores obtidos em tanque Classe "A", além de oferecer vantagens sobre esse tanque tais como: 1) baixo custo de aquisição; 2) facilidade de transporte e instrumentação e 3) redução de erros provocados pelas chuvas.

Erthal (1994) analisou a estimativa da ETo pelos métodos do atmômetro modificado, da equação de Penman, do tanque Classe "A" e do evapotranspirômetro, na região de Viçosa, agrupando e analisando os dados em períodos diários, de 5, 7, 15 e 30 dias. Avaliou-se a correlação entre diferentes métodos e o atmômetro e, também, a razão entre os valores obtidos no atmômetro e 
nos diferentes métodos e concluiu que o atmômetro modificado simula a ETo estimada pelo tanque Classe "A" e pela equação de Penman, com boa correlação para períodos de sete dias e para períodos mais longos e, no período chuvoso, os resultados obtidos com o atmômetro foram coerentes com a equação de Penman e com a ETo no tanque Classe "A".

Pereira et al. (1994) compararam a evaporação medida com atmômetros modificados e evaporação medida com tanque Classe "A" e evapotranspiração potencial estimada pelo método de Penman, em Piracicaba, utilizando quatro atmômetros: um aparelho com precisão de leitura de $0,5 \mathrm{~mm}$ (aparelho comercializado) e três aparelhos com escala de leitura ampliada, possibilitando uma precisão de $0,15 \mathrm{~mm}$. Fizeram comparações através de regressão linear e observaram que os atmômetros com escala de leitura ampliada apresentaram boa correlação com ETo e ECA, para os diferentes períodos estudados (escala diária e períodos acumulados de 3 e 5 dias) e que, nos dias de ocorrência de chuva, os aparelhos apresentam dados inconsistentes, devido à entrada de água no reservatório.

\subsubsection{UMIDADE DO AR NO INTERIOR DE ESTUFAS}

Estudando o comportamento de estufas com cobertura plástica, na região sul do Brasil, Farias et al. (1993b) encontraram maiores valores de umidade relativa máxima, que ocorreram no período noturno, no interior da estufa, devido a uma maior concentração de vapor d'água. Segundo Robledo De Pedro \& Vicente (1988), isto ocorre devido a pequena permeabilidade do plástico à água e a baixa taxa de renovação do ar no interior da estufa.

De acordo com Montero et al. (1985), de maneira geral, no interior de estufas comparado ao exterior, são encontrados, em média, valores mais 
elevados de umidade relativa no período noturno e da manhã, e valores praticamente iguais, no período mais quente do dia.

\subsubsection{TEMPERATURA DO AR E DO SOLO NO INTERIOR DE ESTUFAS}

A temperatura do ar no interior de estufas está intimamente ligada ao balanço de energia, o qual por sua vez, depende de vários fatores como o tamanho da estufa, as propriedades óticas da cobertura e as condições meteorológicas locais (Buriol et al. 1993).

Durante o dia, devido à radiação líquida positiva, a superfície aquece a parcela de ar próximo a ela, gerando assim um processo convectivo. Dentro da estufa este processo é interrompido pela cobertura plástica que impede a saída do ar quente, o que provoca temperatura altas durante o período diurno. Sendo assim, no interior de estufas, o valor da temperatura máxima pode ser bem maior quando comparada com o exterior (Montero et al., 1985; Mills et al., 1990 e Farias et al. 1993b).

O valor médio da temperatura mínima do ar no interior de estufas cobertas com PEBD tende a ser igual ou ligeiramente superior, quando comparado com o ambiente externo (Montero et al., 1985; Mills et al., 1990; Buriol et al., 1993 e Farias et al., 1993b).

Dependendo das condições atmosféricas, em algumas noites, a temperatura noturna no interior da estufa é menor do que aquela no ambiente externo. Isso pode acontecer em noites com ventos moderados ou fortes associados com céu limpo pois, na condição interior, a perda acentuada de energia e a ausência de turbulência causam uma inversão térmica (Montero et al., 1985; 
Mills et al., 1990; Buriol et al., 1993 e Farias et al., 1993b). Mas Buriol et al. (1993) ressaltam que quando isto ocorre a temperatura noturna é alta, não oferecendo riscos às plantas.

No período noturno, a vedação da estufa pode influenciar no comportamento da temperatura do ar, principalmente em noites com ventos moderados e fortes (Robledo De Pedro \& Vicente, 1988 e Farias et al., 1993b).

Schneider et al. (1993), estudando a modificação na temperatura do solo causada por estufas, encontraram uma temperatura média superior na estufa independente da profundidade e do horário de leitura e as maiores diferenças de temperatura do solo, entre o interior da estufa e o solo externo, ocorreram nos dias frios.

\subsection{COEFICIENTE DE CULTURA}

Segundo Doorenbos \& Pruitt (1977), o coeficiente de cultura (Kc) é o fator que relaciona a evapotranspiração máxima (ETm) de uma cultura em qualquer fase do seu desenvolvimento e sem deficiência hídrica no solo, com a evapotranspiração de referência (ETo) correspondente :

$$
K c=\frac{E T m}{E T o}
$$

Diferentes culturas, sem restrição de umidade, sujeitas à mesma condição climática, deverão sofrer diferentes perdas d'água, devido às diferenças do sistema radicular, estádio de desenvolvimento e área foliar, o que resulta em diferentes valores de coeficientes de cultura (Kc) (Villa Nova, 1983). 
Os coeficientes de cultura variam com o estádio de desenvolvimento da planta, densidade de plantio, condições de umidade e clima. Outro fator de variação do Kc pode ser a latitude, segundo Hanks \& Ascroft (1980).

$\mathrm{O} \mathrm{Kc}$ assume valores baixos na fase de emergência, valores máximos durante o período de desenvolvimento vegetativo e declinam na fase de maturação. Pruitt et al. (1972) constataram que os coeficientes, para uma cultura cultivada sob diferentes condições climáticas e épocas de plantio, podem variar, já que os parâmetros locais, tais como temperatura, umidade relativa, vento, radiação solar e as variações fisiológicas e aerodinâmicas da planta influenciam diretamente a evapotranspiração. O Kc varia, também, com o método de estimativa de ETo (Barbieri, 1981).

Doorenbos \& Pruitt (1977), de modo geral, dividem o ciclo de desenvolvimento das culturas, para o cálculo dos coeficientes de cultura, em quatro fases:

I - fase inicial - compreende a parte do ciclo que vai da germinação até quando a cobertura vegetal alcança $10 \%$ da superfície;

II - fase do desenvolvimento da cultura - que se estende desde $10 \%$ de cobertura até em torno de 70 a $80 \%$ de cobertura vegetal;

III - fase de meia estação - que vai desde o final da segunda fase até o início da maturação ( queda e despigmentação das folhas);

IV - fase final - que se estende do início da maturação à colheita.

Como no caso do crisântemo o produto final de interesse comercial são as próprias flores, a quarta fase é eliminada, visto que a colheita das hastes ou a colocação dos vasos para a venda, dá-se em função do estádio das inflorescências bem antes desta fase. 


\section{MATERIAL E MÉTODOS}

\subsection{ASPECTOS GERAIS.}

O experimento foi realizado de modo a não alterar as formas de plantio e condução da cultura, que seguiram a rotina de produção comercial das plantas de crisântemo cultivadas em vasos.

\subsection{LOCALIZAÇÃO GEOGRÁFICA}

O experimento foi realizado na propriedade denominada Granja Triângulo, no município de Holambra, região de Campinas, distante $140 \mathrm{Km}$ de São Paulo, cujas coordenadas geográficas são: latitude de $22^{\circ}, 33^{\prime}$ sul e longitude $47^{\circ}, 01^{\prime}$ oeste e $686 \mathrm{~m}$ de altitude.

A estufa onde foi instalado o experimento, está disposta no sentido norte-sul, tem área de $4300 \mathrm{~m}^{2}, 5,0 \mathrm{~m}$ de pé direito e cobertura plástica de polietileno transparente, de baixa densidade, com espessura de 100 micra, suportada por estrutura de ferro galvanizado (estufa pré-fabricada). 


\subsection{PREPARAÇÃO DOS VASOS.}

\subsubsection{DESCRIÇÃO DOS VASOS.}

O experimento foi conduzido em vasos cônicos de barro número 15 , com volume aproximado de 1 litro, cujas dimensões médias são:

- diâmetro superior externo $=15 \mathrm{~cm}$;

- diâmetro superior interno $=13 \mathrm{~cm}$;

- diâmetro inferior externo $=8,5 \mathrm{~cm}$;

- diâmetro inferior interno $=6,5 \mathrm{~cm}$; e

- altura $=13 \mathrm{~cm}$

\subsubsection{DESCRIÇÃO DO SUBSTRATO.}

O substrato usado para enchimento dos vasos constituiu-se de uma mistura de solo (36\%), pó de xaxim (32\%) e casca de pinus (32\%).

$\mathrm{Na}$ Tabela 1 são apresentadas as características físicas do substrato, utilizado no presente trabalho.

Tabela 1 - Valor percentual de areia, silte, argila, matéria orgânica e massa específica real do substrato utilizado no preenchimento dos vasos.

\begin{tabular}{|c|c|c|c|c|}
\hline Argila (\%) & Silte (\%) & Areia (\%) & $\begin{array}{c}\text { Matéria } \\
\text { Orgânica (\%) }\end{array}$ & $\begin{array}{c}\text { Densidade de } \\
\text { Partículas do } \\
\text { Solo }\left(\mathrm{g} / \mathrm{cm}^{3}\right)\end{array}$ \\
\hline 29,84 & 15,32 & 31,37 & 23,48 & 2,47 \\
\hline
\end{tabular}




\subsubsection{CULTIVAR}

Para facilitar a coleta de dados, foi escolhido um cultivar de crisântemo que fosse produzido o ano todo.

O cultivar utilizado foi o Puritan, que consiste de uma inflorescência de tamanho grande, de coloração branca e próprio para produção em vasos. Na condução da cultura foi feita a desbrota dos botões surgidos lateralmente nas hastes, de modo a restar apenas uma inflorescência por haste (Figura 1).

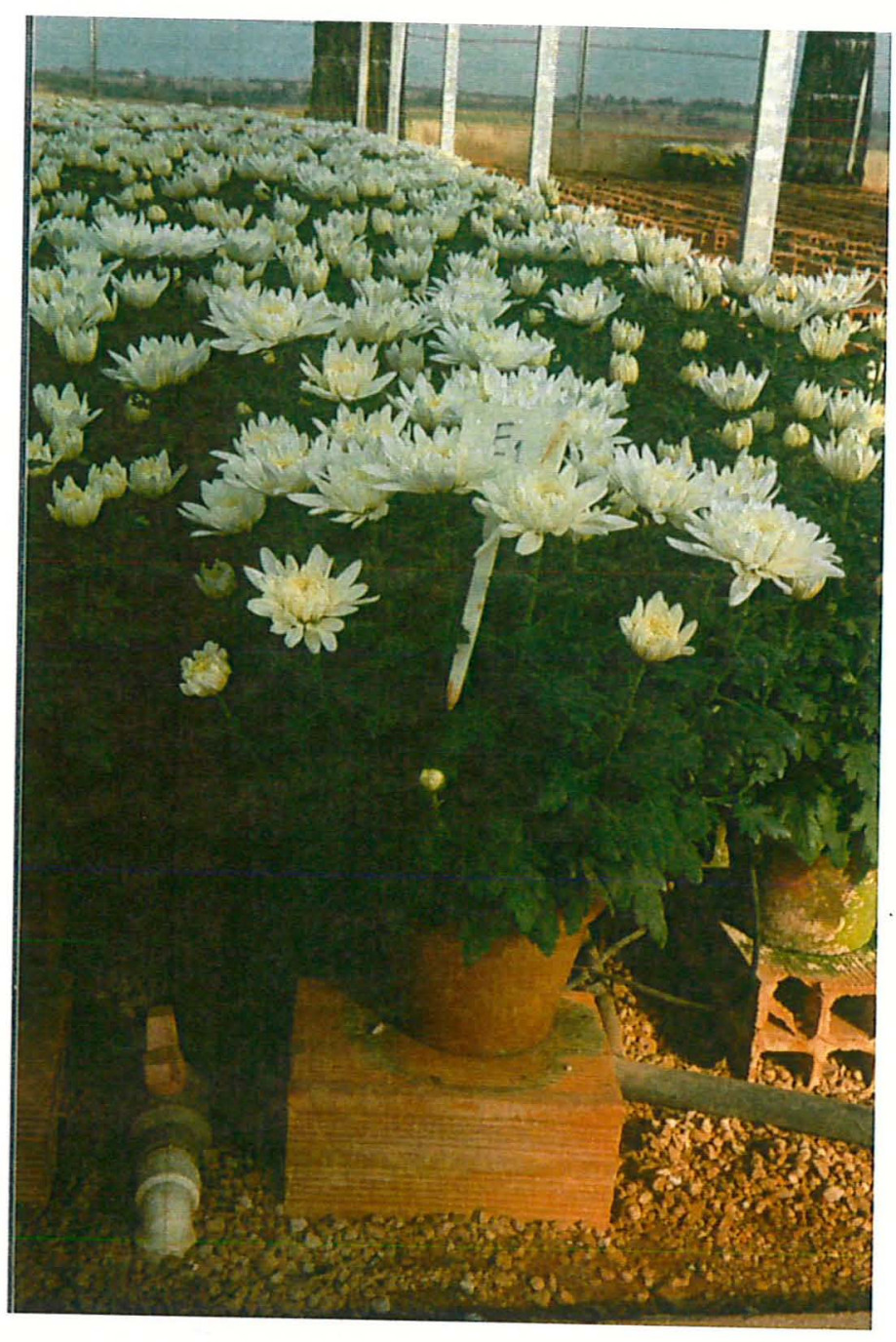

Figura 1 - Vaso de barro com crisântemo. 


\subsubsection{PLANTIO.}

O crisântemo foi plantado nos vasos semanalmente, utilizando-se de mudas fornecidas por um produtor externo à propriedade. Cada vaso recebia seis mudas e esses vasos permaneciam em uma estufa de menor dimensão, onde recebiam um tratamento de iluminação que inibia o florescimento das mudas, ao mesmo tempo que promoviam um maior e mais rápido desenvolvimento de seu sistema radicular. Nesse sentido, as condições de umidade elevada, geradas pela cobertura dos vasos com plástico, após o transplante das mudas e após a irrigação, ajudavam a garantir o enraizamento das mudas.

Nesse local as mudas ficavam, aproximadamente, por duas semanas até serem transferidas para uma estufa maior, onde permaneciam por cerca de 10 semanas. O presente experimento foi conduzido nas condições da estufa maior, desprezando-se as duas primeiras semanas mais voltadas ao enraizamento homogêneo das mudas do vaso.

\subsubsection{IRRIGAÇÃO}

Os vasos, após transferidos para a estufa de produção comercial, foram irrigados por gotejamento, sendo que cada vaso recebeu $1,2 \mathrm{~L}$ de água/hora através de "gotejador com longo percurso integrado", classificado por Bernardo (1989). O manejo da irrigação, em todo o periodo do cultivo seguiu critérios definidos de acordo com o bom senso do produtor, procurando não interferir em sua rotina de produção. 


\subsection{DELINEAMENTO EXPERIMENTAL}

\subsubsection{DESCRIÇÃO DA FORMA DE CONDUÇÃO DA CULTURA DO CRISÂNTEMO E NÚMERO DE ESTÁDIOS.}

O plantio ocorreu uma vez por semana e o tempo para a entrega dos vasos no comércio, foi de 12 semanas, de modo a encontrar-se sempre na estufa, crisântemos com diferenças de plantio de uma semana. Como foram desprezadas as duas primeiras semanas de cultivo em que os vasos ficam em ambiente totalmente diferente do retante do ciclo, sob irrigação por nebulização, além de cobertas com plástico transparente para evitar a evapotranspiração elevada e garantir o enraizamento, optou-se por avaliar a planta iniciando as medições na quarta semana e finalizando na décima segunda semana. No experimento, entretanto, foram utilizados plantas de crisântemo com 2 semanas de diferença de idade entre elas, até a fase de cultivo final, perfazendo 5 estádios (fases) de desenvolvimento da planta analisados.

Utillizou-se também 5 vasos cultivados com grama batatais (Paspalum notatum L.), sob as mesmas condições da cultura e plantada em vasos de barro iguais ao da cultura. Essa grama foi plantada uma única vez, sendo utilizada em todas as épocas do ano em que foram feitas as avaliações para o experimento.

\subsubsection{NÚMERO DE ÉPOCAS DO ANO.}

Procurando obter informações sobre o consumo de água pelo crisântemo cultivado sob diferentes condições climáticas, as avaliações foram repetidas em diversas épocas do ano, conforme cronograma da Tabela 2. 
Tabela 2 - Calendário de avaliações do consumo de água pelo crisântemo.

\begin{tabular}{|c|c|c|c|c|c|c|}
\hline ano & \multicolumn{3}{|c|}{1995} & \multicolumn{3}{c|}{1996} \\
\hline mês & agosto & outubro & dezembro & fevereiro & abril & junho \\
\hline dia & 16,17 e 18 & $17,18,19$ e 20 & $12,13,14$ e15 & $20,21,22$ e 23 & $16,17,18$ e 19 & $18,19,20$ e 21 \\
\hline
\end{tabular}

\subsection{PARÂMETROS A SEREM AVALIADOS.}

\subsubsection{CONSUMO DE ÁGUA.}

Cada vaso foi considerado como se fosse um lisímetro, sendo que a determinação do consumo de água foi feita da seguinte maneira:

-colocou-se água no vaso até à capacidade de retenção de água do vaso; -após uma hora pesou-se o vaso;

-havendo necessidade de nova irrigação, adicionou-se determinada quantidade de água; sendo que o excesso drenado também foi quantificado;

-24 horas após a primeira irrigação, pesou-se o vaso, obtendo-se, pela diferença dos pesos, o volume de água consumido durante um dia.

As pesagens foram feitas em balança de precisão de $1 \mathrm{~g}$, mostrada na Figura 2.

Esta operação foi repetida por três dias consecutivos, em cinco vasos (cinco repetições), em cada um dos cinco estádios considerados, dando um total de setenta e cinco (75) determinações por avaliação, o que levou a 450 determinações, nas seis avaliações realizadas durante todo o experimento. 
Foram também efetuadas medições em cinco vasos com grama batatais, cultivados sob as mesmas condições.

\subsection{2. ÁREA FOLIAR.}

Em todas as épocas de amostragem foram avaliadas as áreas foliares de cada estádio de desenvolvimento da cultura, da seguinte maneira:

- tomou-se o peso seco das folhas dos crisântemos contidos em 3 vasos de cada estádio;

- foram extraídos discos de área conhecida das folhas;

- esses discos, juntamente com o restante das folhas, foram secos em estufa à $60^{\circ} \mathrm{C}$, até peso constante;

- conhecida a relação entre o peso seco e a área foliar do disco, obteve-se, a partir do peso seco das folhas, a área foliar total, por vaso, para cada estádio.

\subsubsection{PARÂMETROS CLIMÁTICOS.}

Mediu-se a evaporação de um tanque Classe A modificado, a evaporação de dois atmômetro com escala de leitura ampliada e o consumo de água pela grama batatais cultivada em vasos, Figuras 3(a) e 3(b). 


\subsubsection{EVAPORAÇÃO}

A evaporação foi avaliada através de um tanque Classe A modificado e da média entre dois atmômetros com escala de leitura ampliada.

O tanque Classe A modificado que, neste trabalho foi denominado tanque reduzido, é de forma cilíndrica com $60 \mathrm{~cm}$ de diâmetro e $25 \mathrm{~cm}$ de altura, com fundo plano, construído inteiramente de chapa galvanizada. São seus complementos um poço tranquilizador de $26 \mathrm{~cm}$ de altura e $10 \mathrm{~cm}$ de diâmetro, em cuja borda se assenta um parafuso micrométrico de gancho, com capacidade para medir variações no nível da água do evaporímetro a partir de $0,02 \mathrm{~mm}$. $\mathrm{O}$ tanque foi instalado sobre um estrado de madeira de $63 \mathrm{~cm}$ de largura por $63 \mathrm{~cm}$ de comprimento e $17 \mathrm{~cm}$ de altura.

O atmômetro com escala de leitura ampliada, modificado por Pereira et al. (1994), nada mais é do que um atmômetro comercial, com precisão das medidas de evaporação ampliadas de $0,5 \mathrm{~mm}$ para $0,15 \mathrm{~mm}$.

Foi instalado diretamente sobre o solo, sendo que a altura da cápsula atingiu a altura do dossel da cultura com idade entre 6 a 8 semanas (desenvolvimento intermediário). 


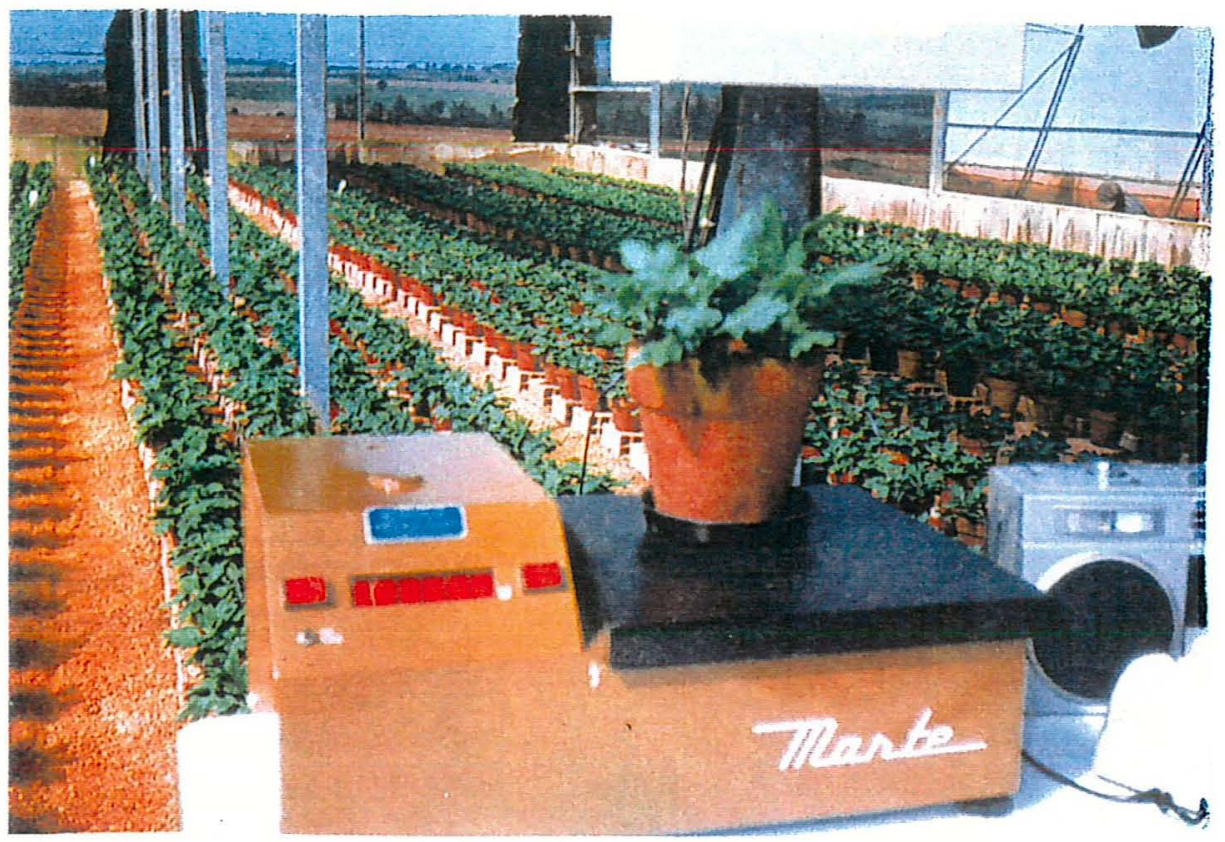

Figura 2 - Balança de precisão de $0,1 \mathrm{~g}$, usada durante as pesagens.

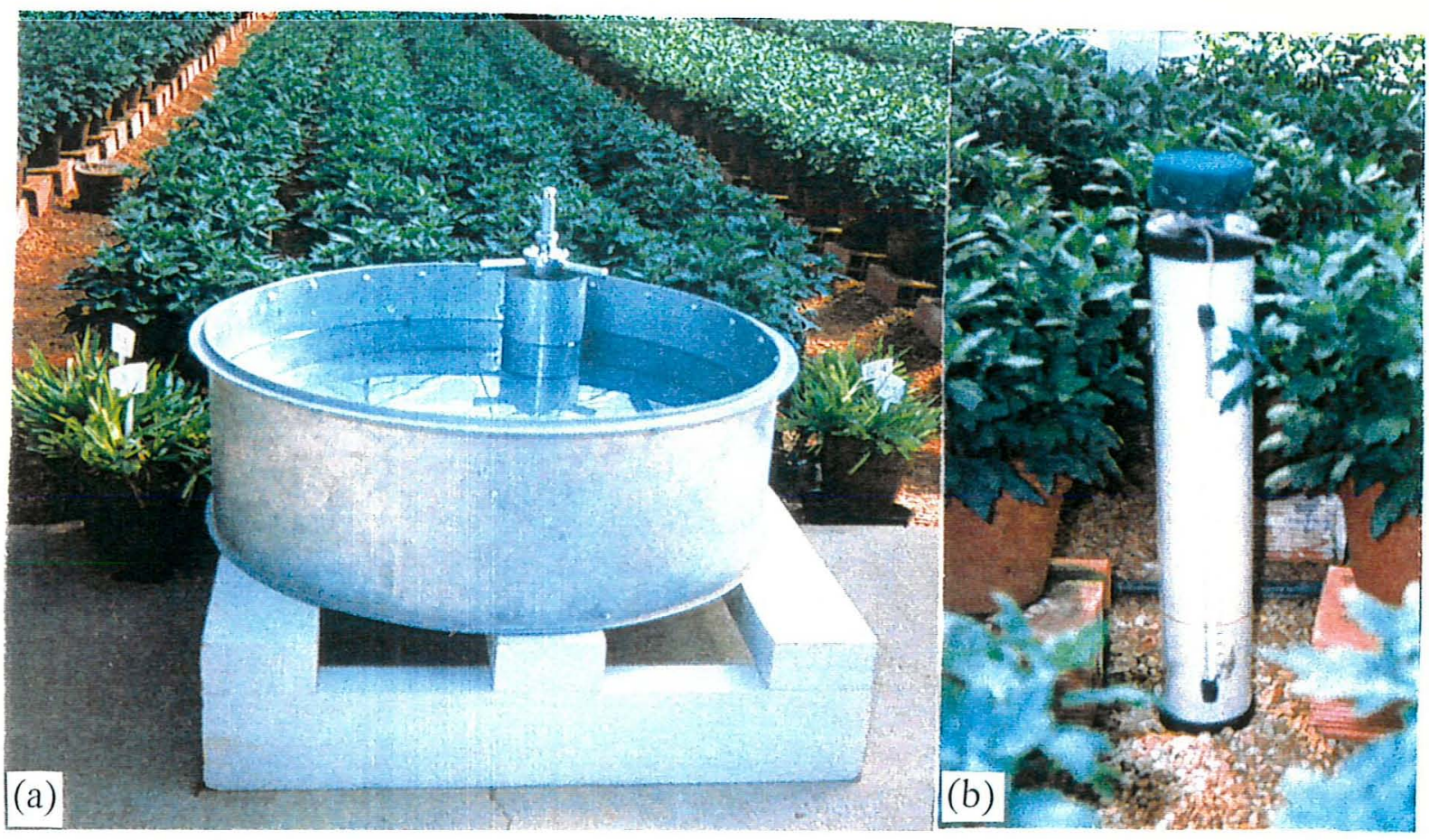

Figura 3 - (a) Tanque reduzido e parafuso micrométrico sobre estrado de madeira, ladeado por vasos com grama. (b) Atmômetro de escala ampliada. 


\subsection{ANÁLISE DOS RESULTADOS.}

A partir dos dados obtidos, foram ajustadas equações, correlacionando o consumo de água pela cultura do crisântemo, a área foliar da cultura em vários estádios de desenvolvimento e a evaporação do tanque reduzido. Foram ajustadas, ainda, equações correlacionado o consumo de água pela cultura, a área foliar e a evaporação do atmômetro de escala ampliada.

Determinou-se, a partir dos dados de consumo de água pelo crisântemo e pela grama batatais, cultivados sob as mesmas condições, um coeficiente de consumo da planta (CC). Estabeleceu-se também, um coeficiente de consumo, adimensionalizando o consumo de água pelo crisântemo com o máximo consumo diário da própria cultura, em uma de suas fases de desenvolvimento (CMA).

Foi ajustada uma equação quadrática, para descrever 0 desenvolvimento da área foliar (AF), em função dos dias após plantio das mudas (DAP), e uma equação polinomial quadrática, que descreve o acúmulo da matéria seca total (MS) por vaso da cultura em função dos dias após o plantio das mudas.

Os ajustes foram feitos considerando cada período de coleta individualmente e, também, considerando todos os períodos das coletas realizadas durante o experimento, originando, além de uma equação para cada período, uma equação única para todo o experimento.

$\mathrm{Na}$ análise do ajuste foram considerados o coeficiente de determinação $\left(\mathrm{r}^{2}\right.$ ou $\left.\mathrm{R}^{2}\right)$ e o índice de concordância (d).

O coeficiente de determinação é calculado pela razão entre a soma de quadrados da regressão e a soma de quadrados dos termos observados, e descreve a proporção da variação total explicada pelo modelo de regressão. $\mathrm{O}$ 
valor de $\mathrm{R}^{2}$ varia entre 0 (zero) e 1 (um) e quanto mais próximo de 1 (um) melhor a performance do modelo de regressão.

De acordo com Willmott \& Wicks (1980), o coeficiente de determinação $\mathrm{R}^{2}$ têm sido largamente utilizado como índice de correlação. No entanto, o $\mathrm{R}^{2}$ não deve ser utilizado individualmente em uma análise de performance, devido ao fato que o $\mathrm{R}^{2}$, muitas vezes, não está relacionado com o tamanho da diferença entre um valor padrão e um valor previsto por modelos de estimativa ou outros mecanismos de medida diferentes do padrão.

O índice de concordância, também chamado de teste $d$, foi proposto e usado por Willmott (1981), e é calculado pela equação:

$$
d=1-\left[\frac{\sum_{i=1}^{n}(P i-O i)^{2}}{\sum_{i=1}^{n}\left(P^{\prime} i|+| O^{\prime} i \mid\right)^{2}}\right]
$$

onde $\mathrm{Pi}$ são os valores previstos e $\mathrm{Oi}$ os valores medidos, sendo $\mathbf{P}^{\prime} \mathbf{i}=\mathbf{P i}-\overline{\mathbf{O}}$ e $\mathbf{O}^{\prime} \mathbf{i}=\mathbf{O} \mathbf{i}-\overline{\mathbf{O}}$. O índice d é mais sensível ao erro sistemático do que $o R^{2}$. A faixa de valores do índice $d$ varia entre 0 (zero) para completa dispersão entre os valores e 1 (um) para uma perfeita concordância.

Este teste reflete o grau ao qual os desvios observados em relação à média correspondem em magnitude e sinal aos desvios previstos em relação ’a média. Não se trata de uma medida de correlação ou associação no sentido formal, mas uma medida do grau a partir do qual as revisões dos modelos estão livres de erros. O teste $d$ é uma medida padronizada, a fim de ser facilmente interpretada e possibilitar comparações cruzadas de suas magnitudes para uma variedade de modelos, independente de unidades. 


\section{RESULTADOS E DISCUSSÃO}

\section{1. ÁREA FOLIAR EM FUNÇÃO DOS DIAS APÓS O PLANTIO DAS MUDAS.}

Para estudar o comportamento do aumento da área foliar em função da idade da planta, coletou-se amostras de plantas de cada um dos 5 (cinco) estádios de desenvolvimento considerados e determinou-se a área foliar (AF). Ajustou-se, por meio de análise de regressão, os dados de área foliar (AF) e dias após o plantio das mudas (DAP) à Equação 3, obtendo-se os parâmetros mostrados na Tabela 3. Esta equação foi ajustada aos dados coletados em cada época do ano e, também, considerando todas as épocas simultaneamente.

As equações ajustadas foram polinomial raiz quadrada, são válidas para o intervalo de 27 a 96 dias após o plantio das mudas (DAP) e seguem o modelo descrito a seguir:

$$
\mathbf{A F}=\mathbf{a}+\mathbf{b} \sqrt{\mathbf{D A P}}+\mathbf{c} . \mathbf{D A P}
$$

sendo: $\quad \mathrm{AF}$ - área foliar, $\mathrm{m}^{2}$;

DAP - dias após o plantio das mudas;

a, b, c - coeficientes de regressão. 
Os parâmetros do ajuste do consumo de água pelo crisântemo (CA), o número de observações $(\mathrm{N})$, os coeficientes de determinação $\left(\mathrm{r}^{2}\right)$ e o índice de concordância (d), estão na Tabela 3.

Tabela 3 - Épocas, número de observações (N), coeficientes de regressão (a, b e c), coeficientes de correlação $\left(\mathrm{r}^{2}\right)$ e índices de concordância $(\mathrm{d})$, das equações da área foliar, em função dos dias após o plantio das mudas.

\begin{tabular}{|c|c|c|c|c|c|c|}
\hline \multirow[b]{2}{*}{ Época } & \multirow[b]{2}{*}{$\mathbf{N}$} & \multicolumn{3}{|c|}{ Coeficientes de regressão } & \multirow[b]{2}{*}{$\mathbf{r}^{2}$} & \multirow[b]{2}{*}{ d } \\
\hline & & $\mathbf{a}$ & b & c & & \\
\hline ago/95 & 05 & -1.53634 & -0.023471 & 0.41386 & $0.8985^{*}$ & 0.869 \\
\hline out/95 & 05 & -0.862126 & -0.012046 & 0.24165 & $0.9830^{* *}$ & 0.996 \\
\hline $\mathrm{dez} / 95$ & 05 & -1.522617 & -0.025279 & 0.43722 & $0.9433^{* *}$ & 0.987 \\
\hline fev/96 & 06 & -1.510174 & -0.019685 & 0.39141 & $0.9797 * *$ & 0.995 \\
\hline $\mathrm{abr} / 96$ & 05 & -1.443809 & -0.023875 & 0.41479 & $0.9827 * *$ & 0.996 \\
\hline jun/96 & 05 & -0.943881 & -0.113241 & 0.25105 & $0.9541^{* *}$ & 0.990 \\
\hline $\begin{array}{l}\text { ago/95, out } / 95, \\
\text { dez } / 95, \text { fev } / 96, \\
\text { abr } / 96, \text { jun } / 96,\end{array}$ & 31 & -1.033632 & 0.283249 & -0.01411 & $0.8794 * *$ & 0.968 \\
\hline
\end{tabular}

* Teste $t$ significativo a $5 \%$ de probabilidade; ** Teste t significativo a $1 \%$ de probabilidade.

A Figura 4 mostra a curva da equação obtida, bem como, os dados medidos para a área foliar, em função dos dias após o plantio das mudas, para todo o período do experimento.

$\mathrm{O}$ indice $\mathrm{d}$ confirmou haver uma boa concordância dos dados estimados da variável área foliar (AF), pela Equação de regressão 3, conforme pode ser observado na Figura 5. 


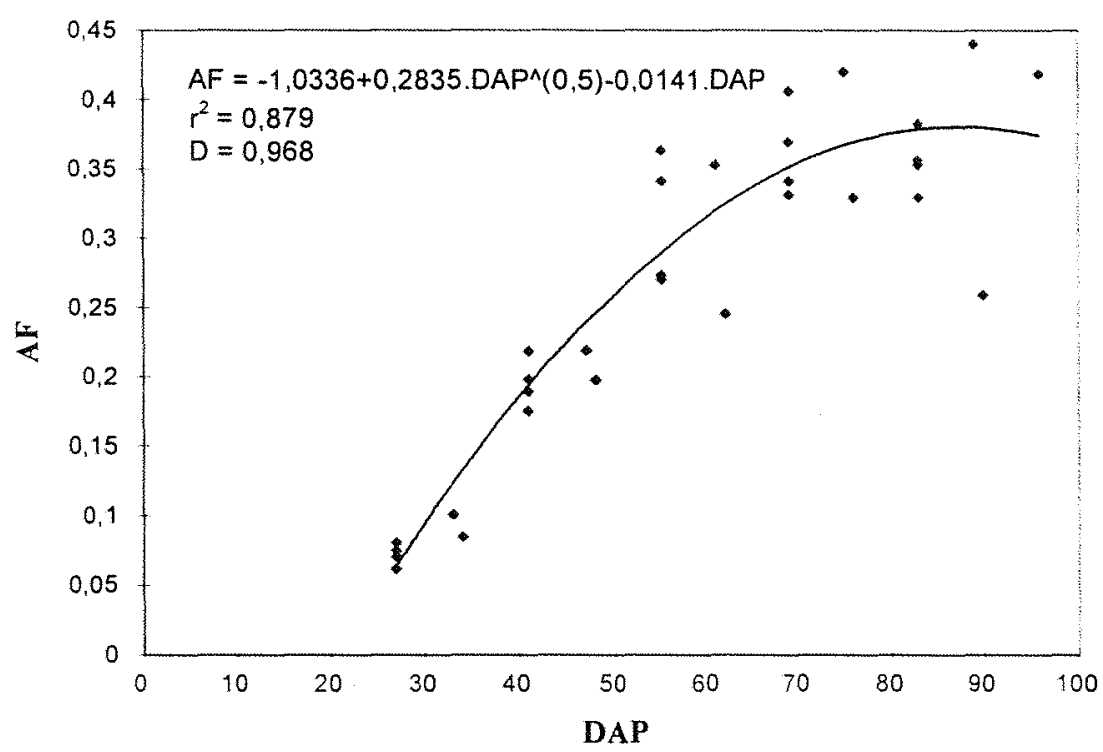

Figura 4 - Representação da correlação entre área foliar e dias após o plantio das mudas, envolvendo todos os dados coletados.

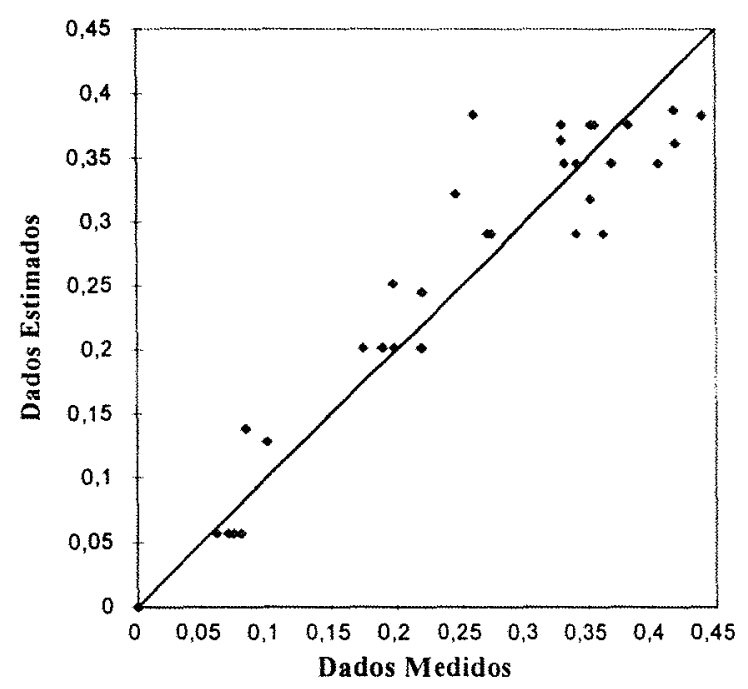

Figura 5 - Dados medidos versus dados estimados pela equação polinomial raiz quadrada da área foliar, em função dos dias após o plantio das mudas, envolvendo todos os dados coletados. 
Pode-se estimar a área foliar das plantas de crisântemo através da equação de regressão que utiliza valores de todos os períodos de coleta de dados, sem que ocorram erros significativos.

\subsection{MATÉRIA SECA DO CRISÂNTEMO}

O acúmulo de matéria seca do crisântemo foi analisado em função dos dias após o plantio das mudas. Houve um acúmulo da matéria seca total, em função dos dias após o plantio das mudas, como pode ser visto na Figura 6.

A equação que envolveu todos os dados experimentais apresentou um coeficiente de correlação $\left(\mathrm{r}^{2}\right)$ de 0,9602 , significativo a $1 \%$ de probabilidade, indicado pelo teste $t$. Pelo teste do grau de adequação (índice de concordância d), obtido com a Equação 2, o valor de 0,975 está indicando haver ótimo grau de estimativa da variável matéria seca, pela equação de regressão.

A análise de cada período de coleta de dado, também foi significativa pelo teste $t$ à $1 \%$ de probabilidade e, o teste $\mathrm{d}$ confirmou a boa concordância dos dados.

Os coeficientes de regressão, o índice de concordância d e o número de dados observados estão na Tabela 4.

Assim, as equações ajustadas foram quadráticas, são validas para o intervalo de 27 a 96 dias após o plantio das mudas (DAP) e seguem o modelo descrito a seguir:

$$
\mathrm{MS}=\mathbf{a}+\mathbf{b} . \mathrm{DAP}+\mathbf{c} \mathrm{DAP}^{2}
$$


sendo: $\quad$ MS - matéria seca total do crisântemo, g;

DAP - dias após o plantio das mudas;

a, b, c - coeficientes de regressão.

Tabela 4 - Épocas, número de observações $(N)$, coeficientes de regressão (a, b e c), coeficientes de correlação $\left(r^{2}\right)$ e índice de concordância (d), das equações da matéria seca do crisântemo, em função dos dias após o plantio das mudas.

\begin{tabular}{|c|c|c|c|c|c|c|}
\hline \multirow[b]{2}{*}{ Época } & \multirow[b]{2}{*}{$\mathbf{N}$} & \multicolumn{3}{|c|}{ Coeficientes de regressão } & \multirow[b]{2}{*}{$r^{2}$} & \multirow[b]{2}{*}{ d } \\
\hline & & $\mathbf{a}$ & b & c & & \\
\hline $\mathrm{ago} / 95$ & 05 & -20.711 & 0.7569 & -0.0022 & $0.9827^{* *}$ & 0.995 \\
\hline out/95 & 05 & -1.838 & 0.0434 & 0.0047 & $0.9978 * *$ & 0.999 \\
\hline $\mathrm{dez} / 95$ & 05 & -14.663 & 0.6765 & -0.0012 & $0.9776^{* *}$ & 0.984 \\
\hline fev/96 & 06 & -16.566 & 0.5766 & 0.0008 & $0.9869 * *$ & 0.997 \\
\hline $\mathrm{abr} / 96$ & 05 & -11.524 & 0.5313 & 0.00003 & $0.9901^{* *}$ & 0.998 \\
\hline jun/96 & 05 & -3.6501 & 0.0435 & 0.006 & $0.9733 * *$ & 0.993 \\
\hline $\begin{array}{l}\text { ago/95, out } / 95, \\
\text { dez } / 95, \text { fev } / 96, \\
\text { abr/96, jun } / 96,\end{array}$ & 31 & -6.4258 & 0.2317 & 0.0033 & $0.9602 * *$ & 0.975 \\
\hline
\end{tabular}

** Teste $t$ significativo a $1 \%$ de probabilidade.

A Figura 7, que confronta os dados estimados com os dados observados, mostra que há uma boa concordância dos dados e uma boa estimativa da matéria seca pela equação proposta (Equação 4). 


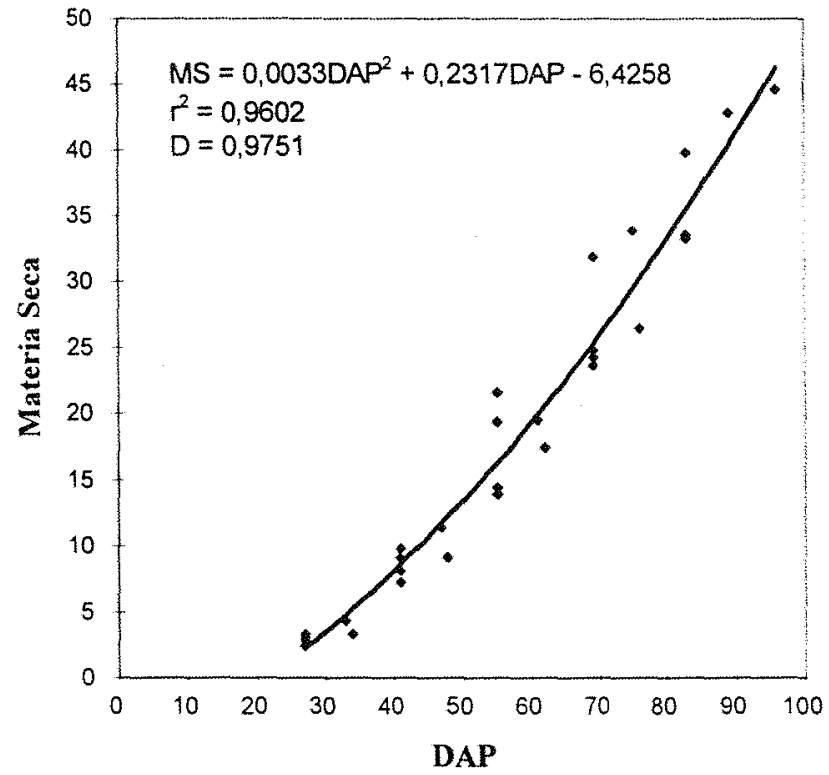

Figura 6 - Matéria seca total do crisântemo em função dos dias após o plantio das mudas, para todos os dados coletados durante o experimento.

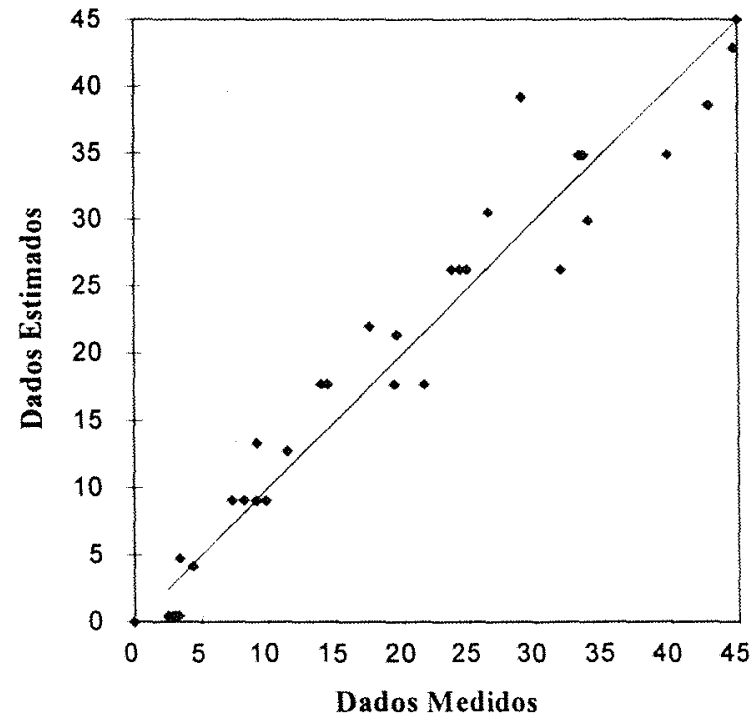

Figura 7 - Dados medidos versus dados estimados pela Equação 4, da matéria seca total do crisântemo em função dos dias após o plantio das mudas, para todos os dados coletados. 


\subsection{COEFICIENTE DE CONSUMO DE ÁGUA PELO CRISÂNTEMO.}

Esse coeficiente foi determinado por meio da relação entre os consumos de água pelas culturas de crisântemo e da grama batatais, cultivadas sob as mesmas condições.

Foram ajustadas equações, correlacionando o coeficiente de consumo de água pelo crisântemo com os dias após o plantio das mudas e todas as equações ajustadas foram quadráticas.

A análise do coeficiente de correlação, juntamente com o índice de concordância (d) não revelou boa concordância dos dados de consumo de água pelo crisântemo, em função dos dados de consumo de água pela grama batatais, quando considerado todo o período analisado.

A equação de regressão desse coeficiente de consumo de água pelo crisântemo $(\mathrm{CC})$, para todos os dados obtidos durante o experimento, em função dos dias após plantio das mudas (DAP), apresentou um coeficiente de correlação de 0,4317 . Apesar do teste $t$ ter sido significativo a $1 \%$ de probabilidade, o gráfico em escala 1:1 entre os dados medidos e dados estimados (Figura 8), indicou não haver boa concordância dos dados e, portanto, a equação não os estima satisfatoriamente, apesar do índice de concordância (d) ter sido considerado bom.

Para os períodos de agosto, outubro e dezembro de 1995, fevereiro, abril e junho de 1996, os testes $t$ também foram significativos a $1 \%$ de probabilidade.

As equações ajustadas, são válidas para o intervalo de 27 a 96 dias após o plantio das mudas e seguem o modelo descrito a seguir: 


$$
\mathrm{CC}=\mathrm{a}+\mathbf{b} \cdot \mathrm{DAP}+\mathbf{c} \cdot \mathrm{DAP} \mathbf{P}^{2}
$$

sendo: $\quad \mathrm{CC}$ - coeficiente de consumo de água pelo crisântemo, $\mathrm{mm} / \mathrm{mm}$;

DAP - dias após o plantio das mudas;

a, b, c - coeficientes de regressão.

Os parâmetros do ajuste estão na Tabela 5

Tabela 5 - Épocas, número de observações $(N)$, coeficientes de regressão (a, b e c), coeficientes de correlação $\left(R^{2}\right)$ e índice de concordância $(d)$ das equações dos dias após o plantio das mudas, em função do coeficiente de consumo de água pelo crisântemo.

\begin{tabular}{|c|c|c|c|c|c|c|}
\hline \multirow[b]{2}{*}{ Época } & \multirow[b]{2}{*}{$\mathbf{N}$} & \multicolumn{3}{|c|}{ Coeficientes de regressão } & \multirow[b]{2}{*}{$\mathbf{r}^{2}$} & \multirow[b]{2}{*}{ d } \\
\hline & & $\mathbf{a}$ & b & c & & \\
\hline ago/95 & 10 & -0.6346 & 0.1024 & -0.0007 & $0.8026 * *$ & 0.907 \\
\hline out $/ 95$ & 15 & -1.0667 & 0.1067 & -0.0008 & $0.7052 * *$ & 0.908 \\
\hline $\mathrm{dez} / 95$ & 15 & -0.1282 & 0.0605 & -0.0004 & $0.6294 * *$ & 0.821 \\
\hline fev/96 & 18 & -0.8199 & 0.0788 & -0.0005 & $0.8183^{* *}$ & 0.943 \\
\hline$a b r / 96$ & 15 & -0.4309 & 0.0669 & -0.0005 & $0.8875^{* *}$ & 0.968 \\
\hline jun/96 & 15 & -0.6076 & 0.0668 & -0.0004 & $0.9140^{* *}$ & 0.976 \\
\hline $\begin{array}{l}\text { ago } / 95, \\
\text { out } / 95, \text { dez } / 95 \text {, } \\
\text { fev } / 96, \text { abr } / 96, \\
\text { jun/ } / 96 .\end{array}$ & 88 & -0.5721 & 0.0755 & -0.0005 & $0.4317 * *$ & 0.785 \\
\hline
\end{tabular}

** Teste $\mathrm{t}$ significativo a $1 \%$ 
A Figura 8 mostra o gráfico de 1:1 dos dados estimados pela curva de regressão, bem como dos dados medidos; verifica-se que há baixa concordância entre esses dados.

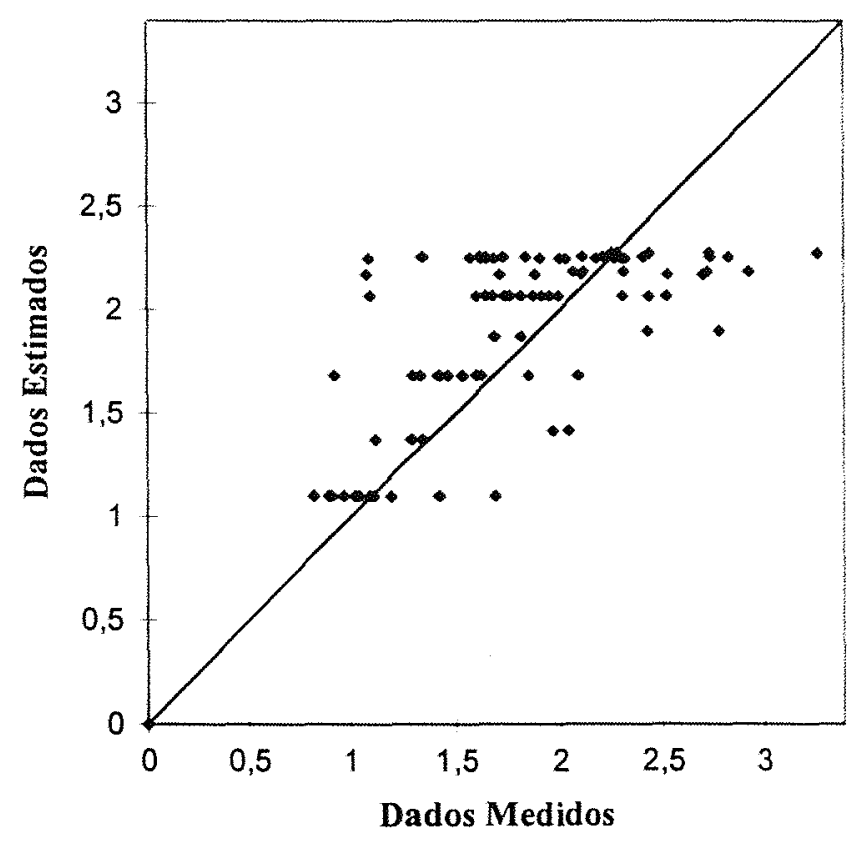

Figura 8 - Dados medidos versus dados estimados pela Equação 5, do coeficiente de consumo de água pelo crisântemo, em função dos dias após plantio das mudas, para todos os dados coletados.

O coeficiente de consumo de água pelo crisântemo se correlacionou com os dias após o plantio das mudas (idades), para os periodos considerados individualmente, pois as condições de desenvolvimento da grama foram as mesmas que as das plantas de crisântemo, nas diferentes idades e no mesmo período. Já ao se considerar todos os períodos simultaneamente, houve baixa correlação, pois as condições de desenvolvimento da grama, em cada período de coleta de dados, diferem-se, exercendo grande influência sobre o consumo da mesma. 
Foi ajustada uma equação de regressão, utilizando-se todos os dados medidos de consumo de água pelo crisântemo (CA), transformados em dados adimensionais, em função dos dias após o plantio das mudas (DAP). O consumo adimensional foi obtido, dividindo-se o consumo de cada estádio de desenvolvimento da cultura pelo consumo de água do estádio de máximo consumo diário (CMX).

$$
\mathrm{CMA}=\frac{\mathrm{CA}}{\mathrm{CMX}}
$$

onde: $\quad$ CMA - coeficiente de consumo de água pelo crisântemo, adimensionalizado pelo máximo consumo diário, $\mathrm{mm} / \mathrm{mm}$;

CA - consumo de água pelo crisântemo, $\mathrm{mm} /$ dia, CMX - consumo de água do estádio de máximo consumo diário, $\mathrm{mm} / \mathrm{dia}$.

As equações ajustadas foram quadráticas, são válidas para o intervalo de 27 a 96 dias após o plantio das mudas (DAP) e seguem o modelo descrito a seguir:

$$
\mathrm{CMA}=\mathbf{a}+\mathbf{b} \cdot \mathbf{D A P}+\mathbf{c . D A P} \mathbf{P}^{2}
$$

sendo: $\quad$ CMA - coeficiente de consumo de água pelo crisântemo, adimensionalizado pelo máximo consumo diário, $\mathrm{mm} / \mathrm{mm}$; DAP - dias após plantio das mudas; 
a, b, c - coeficientes de regressão.

Os parâmetros do ajuste estão na Tabela 6

Tabela 6 - Épocas, número de observações $(N)$, coeficientes de regressão ( $a$, b e c), coeficientes de correlação $\left(\mathrm{R}^{2}\right)$ e índice de concordância (d) das equações dos dias após o plantio das mudas em função do consumo de água pelo crisântemo, adimensionalizado pelo máximo consumo diário.

\begin{tabular}{|c|c|c|c|c|c|c|}
\hline \multirow[b]{2}{*}{ Época } & \multirow[b]{2}{*}{$\mathbf{N}$} & \multicolumn{3}{|c|}{ Coeficientes de regressão } & \multirow[b]{2}{*}{$\mathbf{R}^{2}$} & \multirow[b]{2}{*}{ d } \\
\hline & & $\mathbf{a}$ & b & c & & \\
\hline ago/95 & 10 & -0.1917 & 0.0336 & -0.0002 & $0.8348^{* *}$ & 0.813 \\
\hline out $/ 95$ & 15 & -0.3866 & 0.0386 & -0.0003 & $0.7234^{* *}$ & 0.889 \\
\hline $\mathrm{dez} / 95$ & 15 & -0.0497 & 0.0294 & -0.0002 & $0.7707^{* *}$ & 0.889 \\
\hline fev/96 & 18 & -0.3517 & 0.0339 & -0.0002 & $0.8571^{* *}$ & 0.849 \\
\hline $\mathrm{abr} / 96$ & 15 & -0.2352 & 0.0366 & -0.0003 & $0.9225^{* *}$ & 0.818 \\
\hline jun/96 & 15 & -0.2603 & 0.0289 & -0.0002 & $0.9307 * *$ & 0.876 \\
\hline $\begin{array}{l}\text { ago/95, } \\
\text { out } / 95, \mathrm{dez} / 95, \\
\text { fev/96, abr/96, } \\
\text { jun/96. }\end{array}$ & 88 & -0.1937 & 0.0310 & -0.0002 & $0.7795^{* *}$ & 0.777 \\
\hline
\end{tabular}

** Teste $\mathrm{t}$ significativo a $1 \%$

A regressão e a equação ajustada para todos os dados coletados, são mostradas na Figura 9; com esses dados plotou-se um gráfico, em escala 1:1, para verificar-se a dispersão entre os dados medidos e estimados (Figura 10). 


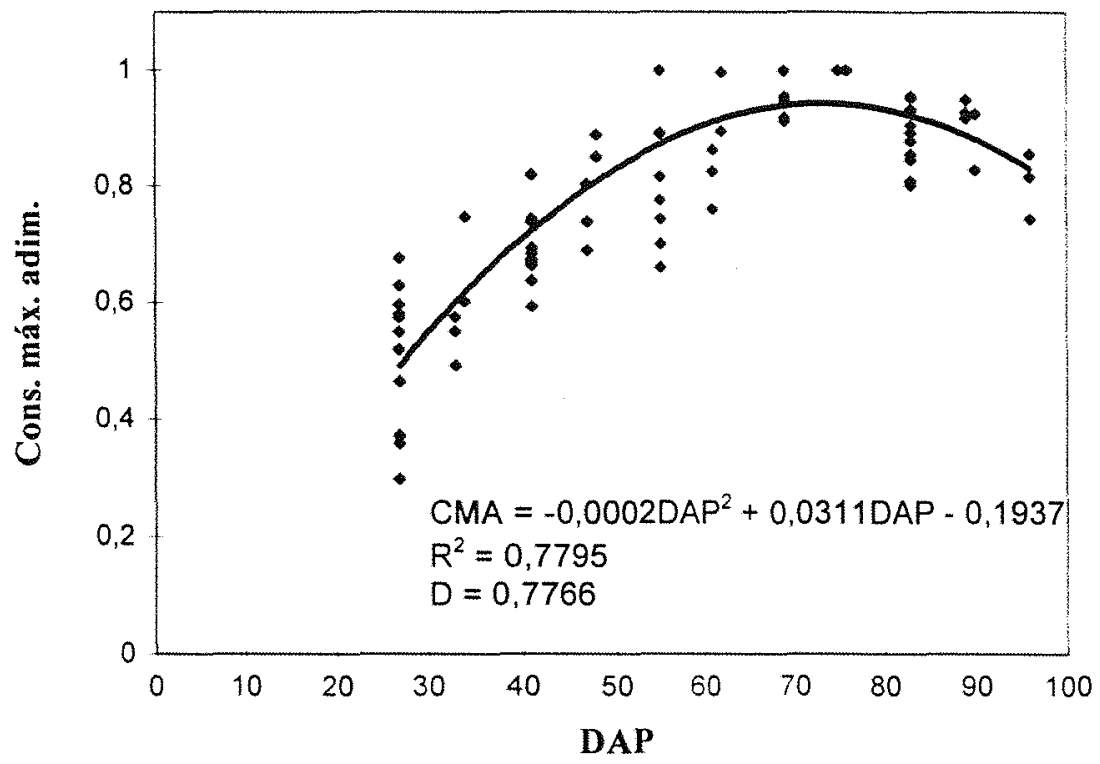

Figura 9 - Representação da correlação entre o consumo de água pelo crisântemo adimensionalizado pelo máximo consumo diário da cultura e dias após o plantio das mudas, envolvendo todos os dados coletados. 


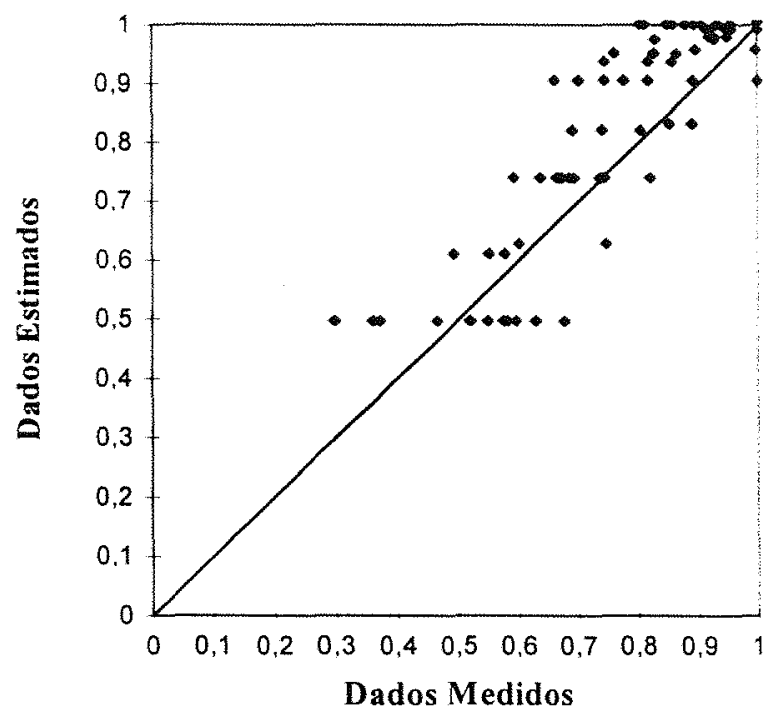

Figura 10 - Dados medidos versus dados estimados de consumo de água pelo crisântemo adimensionalizado pelo máximo consumo diário, envolvendo todos os dados coletados.

A Figura 10 mostra uma melhor concordância de pontos no gráfico $1: 1$, indicando que os dados estimados correlacionam-se com os dados medidos.

O ponto de máximo consumo adimensional de água pelo crisântemo, obtido pela derivada da equação gerada com todos os dados coletados durante o experimento, ocorreu 78 dias após o plantio das mudas.

Assim, para estimar-se os dados de consumo das outras fases da cultura, basta saber a quantidade de água consumida no estádio de máximo consumo e multiplicar pelo consumo adimensional, obtido com o dia após o plantio do crisântemo e os coeficientes gerais de regressão da Equação 6 e Tabela 6. 


\subsection{CONSUMO DE ÁGUA PELO CRISÂNTEMO}

Volpe \& Brunini (1988) relatam que a evapotranspiração máxima da cultura tem correlação direta com o índice de área foliar. Assim, procurou-se estabelecer uma correlação entre os dados de consumo de água pela planta e da área foliar.

\subsubsection{CONSUMO DE ÁGUA PELO CRISÂNTEMO EM FUNÇÃO DA ÁREA FOLIAR E DA EVAPORAÇÃO DO TANQUE CLASSE A MODIFICADO.}

A Equação 7 foi ajustada utilizando-se da análise de regressão envolvendo o consumo de água pela cultura do crisântemo, em função da área foliar (AF) e da evaporação do tanque reduzido (TR). O ajuste foi feito considerando cada período de coleta e também uma única equação, envolvendo todos os dados obtidos durante o experimento.

A Equação 7, utilizando todos os dados obtidos, apresentou um índice $\mathrm{D}$ de 0.8828 e um coeficiente de correlação $\left(\mathrm{R}^{2}\right)$ de 0.6390 e que é significativo a $1 \%$ de probabilidade (tabela 7 ).

Considerando, individualmente, cada período de coleta, os ajustes dos dados à Equação 7 foram melhores que aquele que envolve todo o período. Isto se deve à maior homogeneidade dos dados climáticos.

As equações ajustadas são válidas para área foliar que compreende o intervalo de 27 a 96 dias após o plantio das mudas (DAP) e seguem o modelo descrito a seguir: 


$$
\mathrm{CA}=\mathbf{a}+\mathbf{b} \cdot \mathbf{A F}+\mathbf{c} \cdot \mathrm{TR}
$$

sendo: $\quad$ CA - consumo de água pelo crisântemo, $\mathrm{mm}$;

$\mathrm{AF}$ - área foliar, $\mathrm{m}^{2}$;

TR - evaporação do tanque reduzido, mm;

a, b, c - coeficientes de regressão.

Os parâmetros do ajuste do consumo de água pela cultura estão na Tabela 7.

Tabela 7 - Épocas, número de observações $(\mathrm{N})$, coeficientes de regressão (a, b e c), coeficientes de correlação $\left(R^{2}\right)$ e índice de concordância (d) das equações do consumo de água pelo crisântemo, em função da área foliar e da evaporação do tanque reduzido.

\begin{tabular}{|l|c|c|c|c|c|c|}
\hline \multicolumn{1}{|c|}{ Época } & $\mathbf{N}$ & \multicolumn{2}{c|}{ Coeficientes da regressão } & \multicolumn{1}{c|}{$\mathbf{\text { a }}$} & $\mathbf{R}^{2}$ & $\mathbf{d}$ \\
\hline $\mathrm{ago} / 95$ & 10 & 5.57871 & 28.08360 & 3.77864 & $0.8951^{* *}$ & 0.978 \\
\hline out/95 & 15 & -11.05337 & 28.43133 & 8.63509 & $0.9429^{* *}$ & 0.987 \\
\hline $\mathrm{dez} / 95$ & 15 & -49.68062 & 21.83583 & 29.22637 & $0.8241^{* *}$ & 0.958 \\
\hline $\mathrm{fev} / 96$ & 18 & 8.60783 & 31.27122 & 1.75909 & $0.7067^{* *}$ & 0.921 \\
\hline $\mathrm{abr} / 96$ & 15 & -0.22384 & 24.38614 & 3.81009 & $0.9094^{* *}$ & 0.979 \\
\hline jun/96 & 15 & 0.81177 & 31.32546 & 2.76764 & $0.9106^{* *}$ & 0.979 \\
\hline $\begin{array}{l}\text { ago/95, out/95, } \\
\text { dez/95, fev/96, } \\
\text { abr/96, jun/96. }\end{array}$ & 88 & -2.10623 & 27.91094 & 5.197598 & $0.6390^{* *}$ & 0.883 \\
\hline
\end{tabular}

** Teste $\mathrm{t}$ significativo a $1 \%$ de probabilidade.

A Figura 11 mostra a dispersão dos dados medidos em relação aos dados estimados, considerando todos os dados obtidos durante o experimento. 


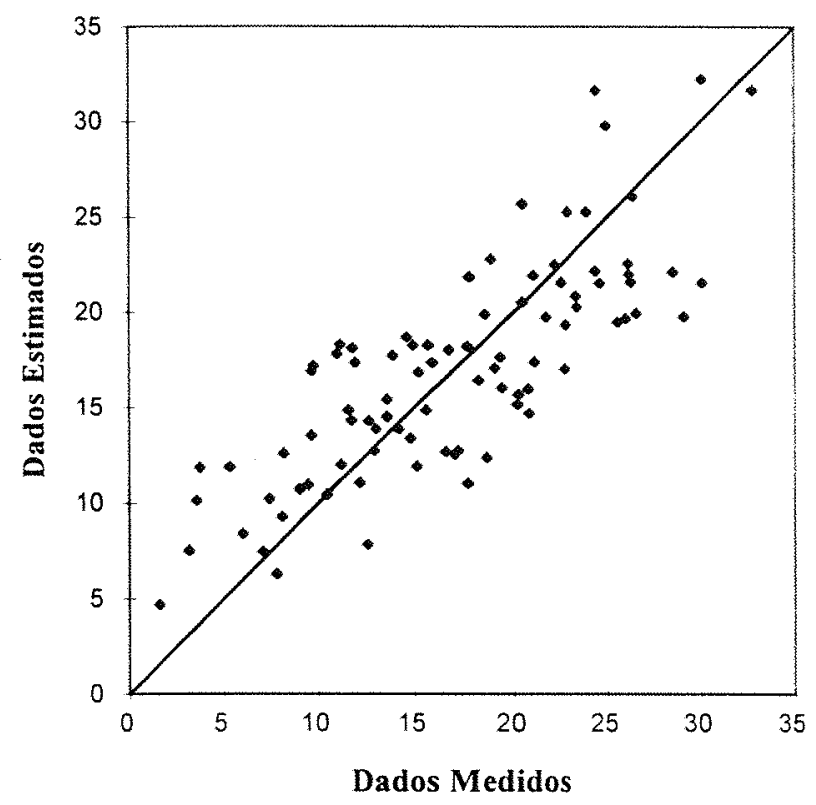

Figura 11 - Dados medidos do consumo de água pelo crisântemo versus dados estimados a partir da área foliar e da evaporação do tanque reduzido, envolvendo todos os dados coletados.

\subsubsection{CONSUMO DE ÁGUA PELO CRISÂNTEMO EM FUNÇÃO DA ÁREA FOLIAR E DA EVAPORAÇÃO DO ATMÔMETRO COM ESCALA DE LEITURA} AMPLIADA.

A Equação 8 foi ajustada, utilizando-se da análise de regressão envolvendo o consumo de água pelo crisântemo, em função da área foliar (AF) e da evaporação do atmômetro de escala ampliada (ATM).

Foram ajustadas equações para cada período de coleta e uma única equação, envolvendo todos os dados obtidos durante o experimento. 
A equação de regressão envolvendo todos os dados coletados apresentou um coeficiente de correlação $\left(R^{2}\right)$ de 0.7400 e um índice de concordância (d) de 0.8773 .

Os coeficientes de determinação $\left(\mathrm{R}^{2}\right)$ e o índice $\mathrm{d}$ apresentaram correlações significativas para todas as análises. $\mathrm{O}$ teste $t$ indicou ser significativo a $1 \%$ de probabilidade, tanto para as análises de cada período, como para a análise geral, envolvendo os dados coletados durante todo o experimento.

Em outubro, em função de problemas com as leituras do atmômetro, em um dos dias do experimento, ocorreu, em decorrência, coeficientes de correlação e de concordância mais baixos que os dos outros meses. Apesar disso, os dados medidos continuaram a apresentar uma boa concordância com os dados estimados pela regressão. Esses dados também provocaram uma pequena redução nos valores dos coeficientes de determinação $\left(R^{2}\right)$ e do índice $d$, para a regressão geral obtida com todos os dados sem, no entanto, afetar, de modo drástico, a sua dispersão.

As equações ajustadas são válidas para área foliar que compreende o intervalo de 27 a 96 dias após o plantio das mudas (DAP) e seguem o modelo descrito a seguir:

$$
\mathrm{CA}=\mathbf{a}+\mathbf{b} . \mathrm{AF}+\mathbf{c . A T M}
$$

sendo: $\quad \mathrm{CA}$ - consumo de água pelo crisântemo, $\mathrm{mm}$;

$\mathrm{AF}$ - área foliar, $\mathrm{m}^{2}$;

ATM - evaporação do atmômetro de escala ampliada x f, mm;

$a, b, c=$ coeficientes de regressão; e

$\mathrm{f}=$ fator de correção de leitura do atmômetro de escala ampliada. 
Os parâmetros do ajuste do consumo do crisântemo (CA), o número de dados observados $(N)$, os coeficientes de determinação $\left(R^{2}\right)$ e o índice d, estão na Tabela 8.

Tabela 8 - Épocas, número de observações $(\mathrm{N})$, coeficientes de regressão (a, b e c), coeficientes de correlação $\left(\mathrm{R}^{2}\right)$ e índice de concordância (d) das equações do consumo de água pelo crisântemo, em função da área foliar e da evaporação do atmômetro de escala ampliada.

\begin{tabular}{|c|c|c|c|c|c|c|}
\hline \multirow[b]{2}{*}{ Época } & \multirow[b]{2}{*}{$\mathbf{N}$} & \multicolumn{3}{|c|}{ Coeficientes de regressão } & \multirow[b]{2}{*}{$\mathbf{R}^{2}$} & \multirow[b]{2}{*}{ d } \\
\hline & & a & b & c & & \\
\hline ago/95 & 10 & 57.0060 & 28.08360 & -22.67186 & $0.8951 * *$ & 0.978 \\
\hline out $/ 95$ & 15 & -4.48606 & 28.43133 & 7.12936 & $0.6757 * *$ & 0.721 \\
\hline $\operatorname{dez} / 95$ & 15 & -2.30877 & 21.83583 & 6.479528 & $0.8970 * *$ & 0.976 \\
\hline fev/96 & 18 & 3.97481 & 31.27122 & 3.931287 & $0.7818^{* *}$ & 0.944 \\
\hline$a b r / 96$ & 15 & -26.1359 & 24.38614 & 18.65414 & $0.9245^{* *}$ & 0.983 \\
\hline jun/96 & 15 & 8.42512 & 31.32546 & -0.21781 & $0.8872 * *$ & 0.974 \\
\hline $\begin{array}{l}\text { ago/95, out } / 95, \\
\mathrm{dez} / 95, \text { fev } / 96 \\
\mathrm{abr} / 96, \text { jun } / 96\end{array}$ & 88 & -4.22926 & 29.23759 & 0.99944 & $0.7400 * *$ & 0.877 \\
\hline
\end{tabular}

A Figura 12 mostra a dispersão dos dados medidos em relação aos dados estimados, considerando todos os dados obtidos durante o experimento do consumo de água pelo crisântemo, em função da área foliar e da evaporação do atmômetro de escala ampliada. 


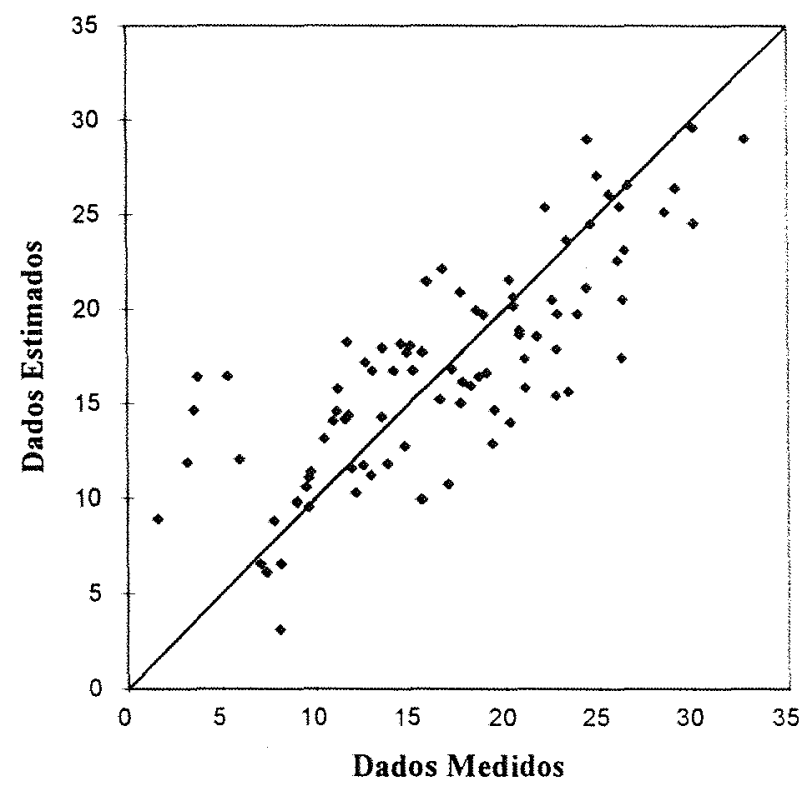

Figura 12 - Dados medidos do consumo de água pelo crisântemo versus dados estimados a partir da área foliar e da evaporação do atmômetro de escala ampliada, envolvendo todos os dados coletados.

Observa-se na Figura 12, que a Equação 8 superestima o consumo de água pela planta para valores entre 0 e $6 \mathrm{~mm}$. 


\section{CONCLUSÕES}

De acordo com os resultados obtidos neste trabalho, pode-se chegar às seguintes conclusões:

1. A área foliar (AF) do crisântemo cultivado em vaso, mantido em casa de vegetação, pode ser estimada, em função dos dias após o plantio das mudas (DAP) $\left(\mathrm{r}^{2}=0.879\right)$.

2. O consumo de água pelo crisântemo (CA) pode ser estimado, a partir dos dias após o plantio das mudas (DAP) e do consumo de água do estádio de máximo consumo diário $(\mathrm{CMX})\left(\mathrm{r}^{2}=0.779\right)$.

3. O consumo adimensional máximo de água pelo crisântemo, considerado o período total, ocorreu 78 dias após o plantio das mudas.

4. O consumo de água pelo crisântemo não se correlacionou com o consumo de água pela grama batatais, mesmo quando cultivados sob as mesmas condições, porque o desenvolvimento vegetativo da grama e do crisântemo, durante o ano, é diferente. 
5. O consumo de água pelo crisântemo (CA) pode ser estimado em função da área foliar (AF) e da evaporação do tanque reduzido $(T R)\left(R^{2}=0.639\right)$

6. O consumo de água pelo crisântemo (CA) pode ser estimado em função da área foliar (AF) e da evaporação do atmômetro com escala de leitura ampliada (ATM) $\left(\mathrm{R}^{2}=0.74\right)$. 


\section{REFERÊNCIAS BIBLIOGRÁFICAS}

AL-RIAHI, M.; AL-KARAGHOULI.; HASSON, A. W. Relations between radiation fluxes of a greenhouse in semi-arid conditions. Agricultural and Forest Meteorology, v.44, p. 329-338, 1989.

ALTHENHOFEN, J. A Modified Atmometer for on farm evapotranspiration determination. In: CONFERENCE ON ADVANCES IN EVAPOTRANSPIRATION, Chicago, 1985. Proceedings. Chicago: ASAE, 1985. p.177-184.

ANDRADE JÚNIOR, A. S. de. Manejo da irrigação na cultura da alface (Lactuca sativa L.) através do tanque Classe A. Botucatu, 1994. 102p. Dissertação (Mestrado) - Faculdade de Ciências Agronômicas, Universidade Estadual Paulista "Júlio de Mesquita Filho".

BARBIERI, V. Medidas e estimativas de consumo hídrico em cana-de-açúcar (Saccharum spp.). Piracicaba, 1981. 82p. Dissertação (Mestrado) - Escola Superior de Agricultura "Luiz de Queiroz", Universidade de São Paulo. 
BARBOSA, J. G.; MARTINEZ, H. F. P. O cultivo hidropônico do crisântemo. Viçosa: Universidade Federal de Viçosa, s.d. 9p.

BAstos, T. X. ; GIAMBELluCA, T. W. ; PACHECO, N. A. ; SÁ, T. D. de A. O Uso do Atmômetro EKERN para Estimar Evaporação em Áreas Muito Chuvosas Na Amazônia: Resultados Preliminares. In: CONGRESSO BRASILEIRO DE AGROMETEOROLOGIA, 8., Santa Maria, 1993. Resumos . Santa Maria: UFSM, 1993. p.103.

BERNARDO, S. Manual de irrigação. 4. ed. Viçosa: UFV, Imprensa Universitária, 1989. 488p.

BLUME, H. R. ; JANTZ, D. R. ; KUDER, L. J. ; SHAW, A. D. Methods in determining crop water usage. St. Joseph: ASAE, 1988. 20p.

BRONER, I. Irrigation scheduling with atmometers. In: INTERNATIONAL CONFERENCE IN IRRIGATION. 5., Tel-Aviv, 1990. Proceedings. Israel, 1990. 9p.

BURIOL, G. A.; SCHNEIDER, F.M.; ESTEFANEL, V.;ANDRIOLO, J. L.; MEDEIROS, S. L.P. Modificação na temperatura mínima do ar causada por estufas de polietileno transparente de baixa densidade. Revista Brasileira de Agrometeorologia, v.1, p.43-49, 1993. 
BURMAN, R. D.; NIXON, P. R.; WRIGHT, J. L.; PRUITT, W. O. Water requeriments. In: JENSEN, $M$. E. Design and operation of farm irrigation system. St Joseph: ASAE, 1980. cap. 5, p. 189-232.

CAVAlCANTE, A. L. Técnica para cultivo do crisântemo. Manchete Rural, n.90, p.8-10, nov. 1994.

DOORENBOS, J.; KASSAM, A. H. Yield response to water. Rome: FAO, 1979. 193p. (FAO. Irrigation and Drainage Paper, 33).

DOORENBOS, J.; PRUITT, J. O. Guidelines for predicting crop water requirements. Rome: FAO, 1977. 179p. (FAO Irrigation and Drainage Paper, 24).

ERTHAL, V. J. Avaliação da estimativa da evapotranspiração de referência utilizando o atmômetro modificado na região de Viçosa. Viçosa, 1994. 44p. Dissertação (Mestrado) - Universidade Federal de Viçosa.

ESTEFANEL, V.; SCHNEIDER, F. M.; BERLATO, M. A.; BURIOL, G. A.; HELDWEIN, A. B. Insolação e radiação solar na região de Santa Maria, RS. I - Estimativa da radiação solar global a partir dos dados de insolação. Rev. Centro de Ciências Rurais, Santa Maria, 1990. 
FARIAS, J.R.B. ; BERGAMASCHI, H. ; MARTINS, S. R. Evapotranspiração no interior de estufas plásticas. Revista Brasileira de Agrometeorologia, v.2, p.17-22, 1994.

FARIAS, J.R.B. ; BERGAMASCHI, H. ; MARTINS, S. R. ; BERLATO, M.A. Efeito da cobertura plástica de estufa sobre a radiação solar. Revista Brasileira de Agrometeorologia, v.1, p.31-36, 1993a.

FARIAS, J.R.B. ; BERGAMASCHI, H.; MARTINS, S. R. ; BERLATO, M.A.; OLIVEIRA, A.C.B. Alterações na temperatura e umidade relativa do ar provocadas pelo uso de estufa plástica. Revista Brasileira de Agrometeorologia, v.1, p.51-62, 1993 b.

FERREIRA, W. A. Utilização da evaporação "Piche" na estimativa da evaporação potencial. Botucatu, 1972. 72p. Tese (Doutorado) - Faculdade de Ciências Médicas e Biológicas de Botucatu, Universidade Estadual Paulista "Júlio de Mesquita Filho".

GLOECKNER, F.C. Chrysanthemum manual. New York: 1985. 189p.

HANAN, J.J.; HOLEY, W.D.; GOLDSBERRY, K.L. Greenhouse management. Berlin : Springer-Verlag, 1978. 530p. 
HANKS, R. J.; ASCROFT, G.L. Soil-plant-atmosphere relations. In: HANKS, R. J.; ASCROFT, G. L. Applied soil physics soil water and temperature aplications. Berlin: Springer-Verlag, 1980. v.1, cap.4, p.111-113.

JENSEN, M. E. (Ed.) Consumptive use of water and irrigation water requirements. New York: ASCE, 1973. 215p.

JOLLIET, O.; BAILEY, B. J. The effect of climate on tomato transpiration in greenhouses : Measurements and model comparisons. Agricultural and Forest Meteorology, v.58, p.43-62, 1992.

KAMPF, A. N. Floricultura: um negócio lucrativo. Trigo e Soja, v. 102, p.3-4, 1989.

KAMPF, E.; BAJAK, E.; JANK, M. S. O Brasil no mercado internacional de flores e plantas ornamentais. Informe GEP/DESR, v.3, n.4, p.3-11, abr. 1990.

LAW, R. A. P. Manejo da irrigação com atmômetros. Engenharia Rural, v.1., n. 2, p. 77-91, dez., 1990.

LAW, R. A. P. ; ISRAELI, I. Evaluation of atmometer performance as a tool for irrigation scheduling. St. Joseph: ASAE, 1988. 26p. 
MARTIN, E. C.; ROBLEDO, L. V. Aplication de los plásticos en la agricultura. Madrid: Mundi-Prensa, 1981.55p.

MARTIN, E.C.; NOVOA, A. C.; GOMES, S. J. Estudio compartivo de las propriedades de diversos materiales utilizados como cobertura en cultivos protegidos. Revista de Plásticos Modernos, v.308, p.185-189, 1982.

MARTINS, G. Uso da casa-de-vegetação com cobertura plástica na tomaticultura de verão. Jaboticabal, 1992. 98p. Tese (Doutorado) - Faculdade de Ciências Agrárias, Universidade Estadual Paulista "Júlio de Mesquita Filho".

MERCADO das flores. Informativo Semanal Cacex-Banco do Brasil, v. 22, n.1057, p.4-13, dez. 1987.

MILLS, P.J.W.; SMITH, I.E.; MORAIS, G. A greenhouse design for a cool subtropical climate with winters based on microclimatic measurements of protected environments. Acta Horticulturae, n.281, p.83-93, 1990.

MONTERO, J. I.; ANTÓN, A. Greenhouse cooling during warm periods. Acta Horticulturae, n.357, p.49-61, 1994.

MONTERO, J. I. ; CASTILLA, N.; GUTIERREZ de RAVÉ, E.; BRETONES, F. Climate under plastic in the Almeria. Acta Horticulturae, n.170, p.227-234, 1985. 
NATIONAL CONFERENCE ON ADVANCES IN EVAPOTRANSPIRATION, Chicago, 1985. Proceedings. Chicago: ASAE, 1985. 453p.

PELÚZIO, J. B. E. Crescimento da alface (Lactuca sativa L.) em casa-devegetação com seis níveis de água e cobertura do solo com seis filmes coloridos de polietileno. Viçosa, 1992. 102p. Dissertação (Mestrado) Universidade Federal de Viçosa.

PENMAN, H. L. Evaporation: an introduction survey. Netherlands. Journal of Agricultural Science, v.4, p.9-29, 1956.

PEREIRA, A. R. Apontamentos da disciplina LFM 704 - evapo(transpi)ração. ESALQ, Departamento de Física e Meteorologia, Piracicaba, 1994.91p.

PEREIRA, A. S. i COELHO, R. D. Determinação da Evapotranspiração de Referência (Eto) Através de Atmômetros modificados em condições Tropicais. In: CONGRESSO BRASILEIRO DE ENGENHARIA AGRÍCOLA, 21., Santa Maria, 1992. Anais. Santa Maria: SBEA, 1992. p.636-647.

PEREIRA, A. S. ; COELHO, R. D.; FOLEGATTI, M. V. Evaporação Medida com Tanque Classe 'A' e evapotranspiração Potencial Estimada pelo Método de Penman. In: CONGRESSO BRASILEIRO DE ENGENHARIA AGRÍCOLA, 23., Campinas, 1994. Anais. Jaboticabal : SBEA, 1994. p.93. 
PERES, J. G. Avaliação do modelo de Penman-Monteith, padrão FAO, para estimar a evapotranspiração de referência nas condições climáticas do Estado de São Paulo. Piracicaba, 1994. 116p. Tese (Doutorado) - Escola Superior de Agricultura "Luiz de Queiroz", Universidade de São Paulo.

PEZZOPANE, J. E. M. Uso de estufa com cobertura plástica e de quebra ventos na produção de porta-enxertos de seringueira, na região de Campinas, S.P. Piracicaba, 1994. 86p. Dissertação (Mestrado) - Escola Superior de Agricultura "Luiz de Queiroz", Universidade de São Paulo.

PRUITT, W. O.; LOURENCE, F. J.; VON OETTINGEN, S. Water use by crops as affected by climate and plant factors. California Agriculture, v.26, p.10$14,1972$.

REISSER JUNIOR, C.; BURIOL, G. A.; ESTEFANEL, V. Estimativa da evapotranspiração máxima diária da alface através da radiação solar global incidente. In: CONGRESSO BRASILEIRO DE AGROMETEOROLOGIA, 7., Viçosa, 1991. Resumos. Viçosa: SBA, 1991. p.233-234.

ROBLEDO DE PEDRO, F. Lâminas de polietileno y copolimero EVA para usos en agricultura. Hojas Divulgadoras, n. 2, p.1-20, 1987.

ROBLEDO DE PEDRO, F.; VICENTE, L.M. Aplicacion de los plasticos en la agricultura. 2: ed. Madrid : Mundi-Prensa, 1988. 573p. 
ROSENBERG, N. J.; McKENNEY, M. S.; MARTIN, P. Evapotranspiration in a greenhouse-warmed world: A review and a simulation. Agricultural and Forest Meteorology. v. 47, p.303-320, 1989.

SANTOS, U. B. Efeito da irrigação por gotejamento no crescimento e produção do tomateiro (Lycopersicon esculetum MILL) cultivado em casa-devegetação e em condições de campo. Piracicaba, 1986. 76p. Dissertação (Mestrado) - Escola Superior de Agricultura "Luiz de Queiroz", Universidade de São Paulo.

SCHNEIDER, F.M.; BURIOL, G. A.; ANDRIOLO, J. L.; ESTEFANEL, V.; STRECK, N.A. Modificações na temperatura do solo causada por estufas de polietileno transparente de baixa densidade em Santa Maria, RS. Revista Brasileira de Agrometeorologia, v.1, p.37-42, 1993.

SEDIYAMA, G. C. Necessidade de água para os cultivos. Brasilia: ABEAS, 1987. 143p. (Curso de Engenharia de Irrigação. Módulo 4).

SILVA, A. A. G. da. Avaliação da eficiência de métodos de estimativa da evapotranspiração de referência para o município de Parnaíba - Pi. Piracicaba, 1989. 80p. Dissertação (Mestrado) - Escola Superior de Agricultura "Luiz de Queiroz", Univerasidade de São Paulo. 
SMITH, M., (Ed.) Report on the expert consultation on procedures for revision of FAO guidelines for predictions of crop water requirements. Rome: FAO, 1991.45p.

TEODORO, R. E. F. Efeito da irrigação no crescimento e produçãode pimentão (Capsicum annuum L.) conduzido em casa-de-vegetação e em condições de campo. Piracicaba, 1986. 67p. Dissertação (Mestrado) - Escola Superior de Agricultura "Luiz de Queiroz", Universidade de São Paulo.

THORNTHWAITE, C. W. An approach toward a rational classification of climate. Geographical Review, v.38, p.55-94, 1948.

VILLA NOVA, N. A. Principais métodos climáticos de estimativa de aplicação de água de irrigação. Piracicaba. ESALQ, Departamento de Física e Meteorologia, 1983. 22p.

VILLA NOVA, N. A.; REICHARDT, K. Evaporação e evapotranspiração. In: RAMOS, F.; OCCHIPINTI, A. G.; VILLA NOVA, N. A.; REICHARDT, K.; MAGALHÃES, P. C. de; CLEARY, R. N. Engenharia hidrológica. Rio de Janeiro: UFRJ, 1989. cap.3, p.143-197.

VOLPE, C. A., BRUNINI, O. Estimativa da resistência aerodinâmica ao fluxo do vapor de água sobre a cultura de milho (Zea mays L.). Ciência Agronômica, v.3, n.2, p.1-2, 1988. 
YANAGISAWA, S. S. Flores: poucos fazem uma análise minuciosa do mercado. Informe GEP/DESR, v.5, n.9, p.7, 1992.

WILLMOTT, C. J. ; WICKS, D. E. An empirical method for the spatial interpolation of monthiy precipitation within California. Physical Geography, v.1, p. 59-73, 1980.

WILLMOTT, C. J. On the validation of models. Physical geography, v.2, n.2, p. 184-94, 1981. 